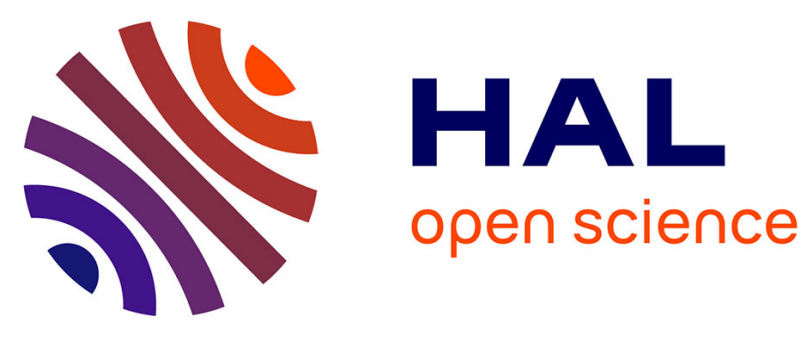

\title{
Design and synthesis of fused tetrahydroisoquinoline-iminoimidazolines
}

Valeria Moas Heloire, Nicolas Renault, Vânia Batalha, Angela Rincon Arias, Mathieu Marchivie, Saïd Yous, Noémie Deguine, Luc Buee, Philippe Chavatte, David Blum, et al.

\section{To cite this version:}

Valeria Moas Heloire, Nicolas Renault, Vânia Batalha, Angela Rincon Arias, Mathieu Marchivie, et al.. Design and synthesis of fused tetrahydroisoquinoline-iminoimidazolines. European Journal of Medicinal Chemistry, 2015, 106, pp.15-25. 10.1016/j.ejmech.2015.10.030 . hal-02060788

\section{HAL Id: hal-02060788 https://hal.science/hal-02060788}

Submitted on 8 Mar 2019

HAL is a multi-disciplinary open access archive for the deposit and dissemination of scientific research documents, whether they are published or not. The documents may come from teaching and research institutions in France or abroad, or from public or private research centers.
L'archive ouverte pluridisciplinaire HAL, est destinée au dépôt et à la diffusion de documents scientifiques de niveau recherche, publiés ou non, émanant des établissements d'enseignement et de recherche français ou étrangers, des laboratoires publics ou privés.

\section{(c)(1)}

Distributed under a Creative Commons Attribution| 4.0 International License 


\section{DESIGN AND SYNTHESIS OF FUSED TETRAHYDROISOQUINOLINE- IMINOIMIDAZOLINES}

Valeria Moas-Héloire ${ }^{\mathrm{a}, \mathrm{b}}$, Nicolas Renault ${ }^{\mathrm{a}, \mathrm{b}}$, Vania Batalha ${ }^{\mathrm{c}}$, Angela Rincon Arias ${ }^{\mathrm{e}}$, Mathieu Marchivie $^{\mathrm{d}}$, Said Yous ${ }^{\mathrm{a}, \mathrm{e}}$, Noémie Deguine ${ }^{\mathrm{a}}$, Luc Buée ${ }^{\mathrm{a}, \mathrm{e}}$, Philippe Chavatte ${ }^{\mathrm{a}, \mathrm{f}}$, David Blum ${ }^{\mathrm{a}, \mathrm{e}}$, Luisa Lopes $^{\mathrm{c}}$, Patricia Melnyk $\mathrm{k}^{\mathrm{a}, \mathrm{e}, *}$ and Laurence Agouridas ${ }^{\mathrm{a}, \mathrm{e}, \text { * }}$

${ }^{a}$ Université de Lille, F-59000 Lille, France

${ }^{b}$ UDSL, EA 4481, UFR Pharmacie, F-59000 Lille, France

${ }^{c}$ Instituto de Medecina Molecular, 1640-028, Lisbon, Portugal

${ }^{d}$ Université Bordeaux, CNRS FRE3396, F-33000 Bordeaux, France

e Inserm UMR-S1172, JPArc, F-59000 Lille, France

${ }^{f}$ Inserm UMR 995, LIRIC, F-59000 Lille, France

Mail address: UFR Pharmacie, 3 rue du Pr Laguesse, BP83, 59006 Lille

List of e-mail addresses: valeria.heloire-2@univ-lille2.fr, nicolas.renault-3@univ-lille2.fr, vanialnbatalha@gmail.com, ararias@quim.ucm.es, mathieu.marchivie@icmcb.cnrs.fr, said.yous@univ-lille2.fr,_noemie.deguine-2@univ-lille2.fr,_luc.buee@inserm.fr, philippe.chavatte@univ-lille2.fr, david.blum@inserm.fr, lvlopes@medicina.ulisboa.pt, patricia.melnyk@univ-lille2.fr, laurence.agouridas@univ-lille2.fr

\section{Corresponding authors:}

Patricia Melnyk, "Onco and NeuroChemistry", Jean-Pierre Aubert Research Center UMRS1172 - Faculté des Sciences Pharmaceutiques et Biologiques (Université Lille 2)

3, rue du Pr Laguesse - BP83 - 59006 Lille Cedex Tel : 33 (0)3 20964949 - fax : 33 (0)3 209649 13. mail: patrica.melnyk@univ-lille2.fr

Laurence Agouridas, "Onco and NeuroChemistry", Jean-Pierre Aubert Research Center UMR-S1172 - Faculté des Sciences Pharmaceutiques et Biologiques (Université Lille 2, 3 rue du Pr Laguesse - BP83 - 59006 Lille Cedex Tel : 33 (0)3 20964368 - fax : 33 (0)3 209649 13. mail: laurence.agouridas@univ-lille2.fr 


\begin{abstract}
In the aim of identifying new privileged structures, we describe the 5-steps synthesis of cyclic guanidine compounds "tetrahydroisoquinoline-iminoimidazolines" derived from tetrahydroisoquinoline-hydantoin core. In order to evaluate this new minimal structure and the impact of replacing a carbonyle by a guanidine moiety, their affinity towards adenosine receptor $\mathrm{A}_{2 \mathrm{~A}}$ was evaluated and compared to those of tetrahydroisoquinoline-hydantoin compounds.
\end{abstract}

KEYWORDS: guanidines, $\mathrm{A}_{2 \mathrm{~A}}$ receptor, privileged structure, iminoimidazoline

Abbreviations: Tic- $\mathrm{H}$, tetrahydroisoquinoline hydantoin; $\mathrm{A}_{2 \mathrm{~A}} \mathrm{R}$, adenosine $\mathrm{A}_{2 \mathrm{~A}}$ receptor. 


\section{Introduction}

In the field of medicinal chemistry, privileged structures are considered as a promising source of ligands able to interact with various targets. ${ }^{1-3}$ In fact, these minimal structures constitute a powerful starting point to identify original compounds by playing with the nature of their substituents. They constitute an anchor point enabling to orientate substituents in various positions, giving access to potentially promising structures and to modulate their affinity and activity. Therefore, identification of novel privileged structures appears as an interesting challenge.

Our group described a series of tetrahydroisoquinoline-hydantoin (Tic-H 1, Figure 1) derived compounds with potent affinity for the sigma-1 receptor in the nanomolar range ensuing various therapeutical in vivo applications. ${ }^{4-9}$ This heterocycle presents an interesting hydrogen bond acceptor group on the hydantoin cycle and is amenable to various decorations. In this study we proposed to identify a new potential privileged structure and decided to evaluate the consequence of replacing the hydantoin's (1) hydrogen bond acceptor by a hydrogen bond donor group resulting in the guanidine moiety of compound 2 (Figure 1). This new heterocycle could be the central core for the design of new active compounds. Guanidines are present in a large variety of natural products with potent biological activities in many fields ${ }^{10-}$ 13 and more specifically in the central nervous system area. ${ }^{14,15}$

This approach was exemplified by preparing the guanidine derivative "Tic-guanidine" and its derivatives ( 2 to $\mathbf{1 3}$ ) in order to evaluate the affinity of this new series on the adenosine receptor $\mathrm{A}_{2 \mathrm{~A}} \mathrm{R} .{ }^{16} \mathrm{In}$ fact, in addition to its affinity towards sigma-1 receptor, Tic-H 1 showed a promising affinity constant towards adenosine receptor $A_{2 A}\left(K_{i}=44 \mu M\right)$. This receptor is widely expressed in the central nervous system. Expressed at different levels (neurons, astrocytes, microglial cells), ${ }^{17-21}$ it acts at various levels of regulation. ${ }^{22-25}$ Therefore, $\mathrm{A}_{2 \mathrm{~A}} \mathrm{Rs}$ are viewed as promising targets in various neurodegenerative diseases, mainly Parkinson's and Alzheimer's diseases. ${ }^{26-28}$

Docking studies, based on the crystal structure of $\mathrm{A}_{2 \mathrm{~A}}$ bound to the high affinity antagonist $(\mathrm{ZM} 241385),{ }^{29}$ showed that Tic-guanidine restored hydrogen bonds that were missing for Tic$\mathrm{H}$ leading us to expect a better affinity of these compounds. ${ }^{30}$

We therefore aim to develop a new series of Tic-guanidine compound. We set up an original and efficient chemical synthesis allowing pharmacomodulations. These latter concern the 
nature of the substituents on the original tricyclic structure Tic-guanidine (series A, figure 1) but also modifications by opening of the central cyclic core (series B, figure 1).

\section{Figure 1.}

\section{Results and discussion}

\subsection{Modeling studies}

Jaakola et al. published in 2008 a crystal structure of $\mathrm{A}_{2 \mathrm{~A}} \mathrm{R}$ with the high affinity antagonist ZM241385. ${ }^{29}$ Tic-H and Tic-guanidine were both docked in $\mathrm{A}_{2 \mathrm{~A}} \mathrm{R}$ 's binding site. Results showed both molecules place in a same manner as ZM241385 does (Figure 2). Mainly, important hydrogen bonds with Glu ${ }^{169}$ and $\mathrm{Asn}^{253}$ missing in the case of Tic- $\mathrm{H}$ are being restored with the guanidine function. Finally, upper carbonyl moiety of Tic-H was not maintained, as it doesn't seem to play an essential role in the interactions with amino acids of the binding site.

\section{Figure 2.}

Supported by our docking studies, pharmacomodulations were envisaged: various $\mathrm{N}$ substituents on the guanidine core (series $A$, figure 1) and opening of the central tricyclic core (series $B$, figure 1). Series $A$ enables to evaluate the effect of the modification of the benzyl group in the hydrophobic upper pocket of the binding site. On the other hand, series $B$ was prepared in order to evaluate the importance of the central core's nature and especially how its geometry impacts compounds' affinity. We wanted to establish whether a planar conformation was essential as described in many $\mathrm{A}_{2 \mathrm{~A}}$ 's antagonists ref or if less restricted structures could improve affinity as compared to already published non planar $\mathrm{A}_{2 \mathrm{~A}}$ antagonists ref. Finally, B series would bring additional informations on structure activity relationships of our Tic-guanidine compounds.

\subsection{Chemical synthesis}

Synthesis of Tic-guanidine derivatives of series $A$ and $B$ was achieved thanks to a unique chemical pathway as depicted in Scheme 1. This enabled us to access desired compounds starting from commercially available amino acids and therefore to easily access various 
pharmacomodulations. We optimized the synthetic pathway of compound 2 starting from commercially available Boc-protected L-tetrahydroisoquinoline carboxylic acid I whose chemistry is well mastered in our group., ${ }^{7,9,31}$ Key step of this synthesis was the final formation of the cyclic guanidine. Various methods are described in the literature to access guanidines $^{12}$ and cyclic guanidines ${ }^{32-34}$ but could not be applied to our strategy. Indeed, we previously described the synthesis of Tic-thiohydantoins, which could be an interesting intermediate for the synthesis of these Tic-guanidines. But their chemical and enantiomeric instability precluded their use in this study. ${ }^{35}$ For final formation of guanidine cycle, direct cyclisation of the free diamine in the presence of cyanogen bromide ${ }^{36-42}$ was unsuccessful. Some adjustments were then required and we finally chose to maintain Boc-protection in order to selectively functionalize the free amine of compounds $\mathbf{2 b - 1 3 b}$ with cyanogene bromide. $^{43}$ Expected guanidines were obtained after Boc-deprotection and subsequent cyclization of intermediate.

Synthesis of series $A$ started from Boc-protected L-tetrahydroisoquinoline carboxylic acid $\mathbf{I}$. Corresponding aldehyde was obtained via reduction of Weinreb amide $\mathbf{I I}^{44,45}$ using $\mathrm{LiAlH}_{4}$ in THF at $0{ }^{\circ} \mathrm{C}^{44}$ Reductive amination with appropriate amine in the presence of sodium triacetoxyborohydride in $\mathrm{CH}_{2} \mathrm{Cl}_{2}$ gave expected Boc-monoprotected derivatives $\mathbf{2 b}-\mathbf{6} \mathbf{b} .{ }^{46}$ Free amine of this last compound was then functionalized using cyanogen bromide in ethanol to give corresponding nitrile derivatives. ${ }^{43}$ Finally, guanidine cyclization was achieved thanks to acidic deprotection of the carbamate and in situ cyclization of the intermediate diamine compound with yields from 46 to $88 \%$.

\section{Scheme 1.}

\section{Figure 3.}

Depending on the nature of the amine in the reductive amination step, compounds $\mathbf{2}$ to $\mathbf{6}$ were first obtained (scheme 1), as depicted in figure 3. On the other hand, opening of the upper part of the central cycle while maintaining $N$-benzyl substitution of the guanidine (scheme 2) core resulted from modification of starting amino acid (compounds 7-13, Figure 4). Compound 12, derived from tyrosine, was prepared from $\operatorname{Boc}-\operatorname{Tyr}(t \mathrm{Bu})-\mathrm{OH}$. The tert-butyl protection was removed in the final cyclisation step.

\section{Scheme 2.}




\section{Figure 4.}

Structure of final compounds was confirmed by various analysis methods. LC-MS gave expected mass, discarding the formation of the dimer. FT-IR indicated the disappearance of the nitrile band (2260-2240 $\left.\mathrm{cm}^{-1}\right)$ and appearance of the guanidine $\mathrm{C}=\mathrm{NH}$ bond (1690-1640 $\mathrm{cm}^{-1}$ ) confirming cyclisation of the compound (see supporting informations). Finally, 1D and $2 \mathrm{D}{ }^{1} \mathrm{H}$ and ${ }^{13} \mathrm{C}$ NMR showed appropriate signals and correlations, especially the guanidine $\mathrm{C}=\mathrm{NH}$ bond.

Some of our compounds were able to crystallize. X-ray spectroscopy thus enabled us to confirm the structure and enantiopurity of compounds $\mathbf{2}$ and $\mathbf{3}$ (figure 5) but also compounds 7, 9 and 11 whose absolute configuration was maintained. ${ }^{47}$

On the other hand, crystallographic data showed compound $\mathbf{8}$ was present as a racemic mixture (for details, see supplementary informations). This compound differs from the other ones, as it is $N$-methylated. $N$-methylation was achieved following a protocol described in the literature to be a non-epimerizing route. ${ }^{48}$ However, in our case, the basic conditions of methylation led to a complete racemization.

\section{Figure 5.}

\section{Figure 6.}

\subsection{Affinity of Tic-guanidine compounds}

Affinity of our compounds was evaluated on human $\mathrm{A}_{2 \mathrm{~A}}$ receptor membranes stably expressed in HEK293 cells. Results (table 1) showed no improvement of binding compared to initial Tic-H compound $1(\mathrm{Ki}=44 \mu \mathrm{M})$ except for the tricyclic guanidine substituted with phenylbutylamine $5(\mathrm{Ki}=35 \mu \mathrm{M})$. More specifically, affinity was drastically decreased for open guanidines.

\section{Table 1.}

Except compound $5(35 \mu \mathrm{M})$ that gives an affinity comparable to the one of Tic-H $\mathbf{1}(44 \mu \mathrm{M})$, binding was not improved with our Tic-guanidine compounds. For sure, rigid tricyclic structures are necessary to bind the $\mathrm{A}_{2 \mathrm{~A}} \mathrm{R}$ receptor as open structures ( $\mathbf{7}$ to 13 ) showed no affinity at all. X-ray analysis helped understanding this observation. In fact, as shown in 
figure 5, open Tic-guanidine structures adopt a curved conformation that does not allow the binding of the molecule in the pocket of the receptor whereas tricyclic structures keep a flat conformation. $^{49}$

Concerning the tricyclic structures (2 to 6), we therefore assume the replacement of carbonyle moiety of $\mathbf{1}$ by a hydrogen bond donor does not give us expected improved affinity for the $\mathrm{A}_{2 \mathrm{~A}} \mathrm{R}$.

\subsection{Cytotoxicity of Tic-guanidine compounds}

Cytotoxicity assays have been conducted on SY5Y cells and showed no toxicity of our compounds at $100 \mu \mathrm{M}$ (Table 1).

\section{Conclusion}

As Tic-H core was of interest for the design of various biologically active compounds, we proposed the Tic-guanidine core as a new privileged structure. This work therefore presented a new and efficient synthesis of guanidine cycles derived from amino acids. We applied this concept to the design of $\mathrm{A}_{2 \mathrm{~A}} \mathrm{R}$ ligands. Unfortunately, binding results established that our initial hypothesis was not confirmed: replacement of the hydrogen bond acceptor moiety carbonyl of compound 1 by the hydrogen bond donor guanidine did not improve the affinity for $A_{2 A} R$. Other decorations are needed to improve the affinity for $A_{2 A} R$. Of particular importance is the lack of cytotoxicity of this new scaffold. Thus valorization of this new scaffold for other receptors is currently under evaluation.

\section{Experimental section}

\subsection{General information}

Chemicals and solvents were obtained from commercial sources, and used without further purification unless otherwise noted. Reactions were monitored by TLC performed on Macherey-Nagel Alugram ${ }^{\circledR}$ Sil 60/UV 254 sheets (thickness $0.2 \mathrm{~mm}$ ). Purification of products was carried out by either column chromatography or thick layer chromatography. Column chromatography was carried out on using Macherey-Nagel silica gel (230-400 mesh). Thick layer chromatography was performed on glass plates coated with Macherey-Nagel Sil/UV 254 (thickness $2 \mathrm{~mm}$ ), from which the pure compounds were extracted with the following solvent system: DCM/MeOH(NH$)$, 90:10. NMR spectra were recorded on a Bruker DRX 300 spectrometer (operating at $300 \mathrm{MHz}$ for ${ }^{1}$ Hand $75 \mathrm{MHz}$ for ${ }^{13} \mathrm{C}$ ). Chemical shifts are 
expressed in ppm relative to either tetramethylsilane (TMS) or to residual proton signal in deuterated solvents. Chemical shifts are reported as position $(\delta$ in ppm), multiplicity $(\mathrm{s}=$ singlet, $\mathrm{d}=$ doublet, $\mathrm{t}=$ triplet, $\mathrm{q}=$ quartet, $\mathrm{p}=$ pentet, $\mathrm{dd}=$ double doublet, $\mathrm{br}=$ broad and $\mathrm{m}$ $=$ multiplet $)$, coupling constant $(\mathrm{J}$ in $\mathrm{Hz})$, relative integral and assignment. The attributions of protons and carbons were achieved by analysis of 2D experiments (COSY, HSQC and HMBC). Mass spectra were recorded on a Varian triple quadrupole $1200 \mathrm{~W}$ mass spectrometer equipped with a non-polar C18 TSK-gel Super ODS (4.6 x $50 \mathrm{~mm})$ column, using electrospray ionization and a UV detector (diode array). HRMS-ESI spectra were recorded on a Thermo Scientific Exactive spectrometer. The purity of final compounds was verified by two types of high pressure liquid chromatography (HPLC) columns: C18 Interchrom UPTISPHERE and C4 Interchrom UPTISPHERE. Analytical HPLC was performed on a Shimadzu LC-2010AHT system equipped with a UV detector set at $254 \mathrm{~nm}$ and $215 \mathrm{~nm}$. Compounds were dissolved in $50 \mu \mathrm{L}$ methanol and $950 \mu \mathrm{L}$ buffer $\mathrm{A}$, and injected into the system. The following eluent systems were used: buffer $\mathrm{A}\left(\mathrm{H}_{2} \mathrm{O} / \mathrm{TFA}, 100: 0.1\right)$ and buffer B $\left(\mathrm{CH}_{3} \mathrm{CN} / \mathrm{H}_{2} \mathrm{O} / \mathrm{TFA}, 80: 20: 0.1\right)$. HPLC retention times (HPLC $\left.\mathrm{t}_{\mathrm{R}}\right)$ were obtained at a flow rate of $0.2 \mathrm{~mL} / \mathrm{min}$ for $35 \mathrm{~min}$ using the following conditions: a gradient run from $100 \%$ of buffer A over1 min, then to $100 \%$ of buffer B over the next $30 \mathrm{~min}$. The melting point analyses were performed on Barnstead Electrothermal Melting Point Series IA9200 and are uncorrected. Infrared spectra were performed on Bruker FT-IR spectrometer model $\alpha$. Preparative HPLC were performed using a Varian PRoStar system using an OmniSphere 10 column C18 250 $\mathrm{mm} \times 41.4 \mathrm{~mm}$ Dynamax from Varian, Inc. A gradient starting from $20 \% \mathrm{CH}_{3} \mathrm{CN} / 80 \%$ $\mathrm{H}_{2} \mathrm{O} / 0.1 \%$ formic acid and reaching $100 \% \mathrm{CH}_{3} \mathrm{CN} / 0.1 \%$ formic acid at a flow rate of 80 $\mathrm{mL} / \mathrm{min}$ was used. Optical rotations were measured at $20^{\circ} \mathrm{C}$ on a Perkin-Elmer 343 polarimeter.

Crystallographic data (excluding structure factors) for the structures in this paper have been deposited with the Cambridge Crystallographic Data Centre as supplementary publication 1401476, 1401477, 1401478, 1401480, 1401481 and 1401479. Copies of the data can be obtained, free of charge, on application to CCDC, 12 Union Road, Cambridge CB2 1EZ, UK (fax: +44-(0)1223-336033 or email: deposit@ccdc.cam.ac.uk).

\subsection{Preparation of Weinreb amide compounds.}

4.2.1. General method 1. To a solution of appropriate amino protected carboxylic acid derivative (1 eq.) dissolved in a mixture of $\mathrm{CH}_{2} \mathrm{Cl}_{2}$ and $\mathrm{CH}_{3} \mathrm{CN}(1: 1,3,7 \mathrm{~mL} / \mathrm{mmol}$ of carboxylic acid), EDC (1.3 eq.), HOBt (1.3 eq.), NMM (6.5 eq.) and HN(Me)OMe.HCl (2.1 
eq.) were added. The mixture was stirred at room temperature over 24-72 $\mathrm{h}$ and then evaporated. The resulting crude product was dissolved in $\mathrm{CH}_{2} \mathrm{Cl}_{2}$, washed three times with saturated $\mathrm{NaHCO}_{3}$ solution, three times with $1 \mathrm{M} \mathrm{HCl}$ and once with brine. Organic layer was dried over $\mathrm{MgSO}_{4}$, filtered and concentrated in vacuo. Purification via flash chromatography was performed.

4.2.2. tert-butyl (3S)-3-[methoxy(methyl)carbamoyl]-3,4-dihydro-1H-isoquinoline-2carboxylate (II). According to general method 1, II was obtained as a colorless oil (5.13g, $61 \%) .{ }^{1} \mathrm{H} \mathrm{NMR}\left(\mathrm{CDCl}_{3}, 300 \mathrm{MHz}\right), \delta(\mathrm{ppm})$ indicates the presence of 2 conformers: $7.15-7.20$ $(\mathrm{m}, 4 \mathrm{H}) ; 5.23$ and 4.86 [X part of ABX system (ft, $J=6.0 \mathrm{~Hz}, 0.5 \mathrm{H})$ and $(\mathrm{ft}, J=7.5 \mathrm{~Hz}$, $0.5 \mathrm{H})$ ]; 4.70 and 4.69 [(AB system, $J=16.5 \mathrm{~Hz}, 1 \mathrm{H}, \Delta v=36 \mathrm{~Hz})$ and (AB system, $J=16.5$ $\mathrm{Hz}, 1 \mathrm{H}, \Delta v=123 \mathrm{~Hz})$ ]; 3.85 and $3.78(2 \mathrm{~s}, 3 \mathrm{H}) ; 3.19$ and $3.16(2 \mathrm{~s}, 3 \mathrm{H}) ; 3.19-2.94$ (unresolved $\mathrm{AB}$ part of $\mathrm{ABX}$ system, m, 2H); 1.51 and 1.45 (2s, 9H). ${ }^{13} \mathrm{C} \mathrm{NMR}\left(\mathrm{CDCl}_{3}, 75 \mathrm{MHz}\right), \delta$ (ppm) indicates the presence of 2 conformers: 175.6, 174.9, 173.0,155.3, 154.9, 154.7,135.5, 134.7, 134.2, 133.9, 133.0, 132.9, 132.9, 132.7, 132.1, 129.9, 129.4, 128.8, 127.9, 127.7, 127.6, $127.1,125.8,83.9,81.6,80.4,61.7,61.5,61.3,54.8,53.5,53.2,52.3,50.7$ 45.4, 44.5, 43.4, 32.7, 32.5, 32.2, 30.9, 30.4, 30.1, 29.8, 28.4, 28.3, 28.1. MS $\left(\mathrm{ESI}^{+}\right): \mathrm{m} / \mathrm{z}=321.1[\mathrm{M}, \mathrm{H}]^{+}$ found; $\mathrm{C}_{17} \mathrm{H}_{25} \mathrm{~N}_{2} \mathrm{O}_{4}$ calculated $\mathrm{m} / \mathrm{z}=321.2[\mathrm{M}, \mathrm{H}]^{+}$.

4.2.3. tert-butyl N-[(1S)-1-benzyl-2-[methoxy(methyl)amino]-2-oxo-ethyl]carbamate (7a). According to general method 1, 7a was obtained as a brown oil $(0.94 \mathrm{~g}, 66 \%) .{ }^{1} \mathrm{H}$ NMR $\left(\mathrm{CDCl}_{3}, 300 \mathrm{MHz}\right), \delta(\mathrm{ppm}): 7.29-7.12(\mathrm{~m}, 5 \mathrm{H}) ; 5.18$ and 5.03-4.86 [X part of ABX system $(\mathrm{d}, J=6.0 \mathrm{~Hz}, 0.5 \mathrm{H})$ and $(\mathrm{m}, 0.5 \mathrm{H}$ ]; $3.65(\mathrm{~s}, 3 \mathrm{H}) ; 3.16(\mathrm{~s}, 3 \mathrm{H}) ; 2.95$ [AB part of ABX system $(\mathrm{dd}, J=12.0$ and $6.0 \mathrm{~Hz}, 1 \mathrm{H})$ and $(\mathrm{dd}, J=15.0$ and $9.0 \mathrm{~Hz}, 1 \mathrm{H}), \Delta v=60 \mathrm{~Hz}] ; 1.39(\mathrm{~s}, 9 \mathrm{H}){ }^{50}$ 4.2.4. tert-butyl N-[(1S)-1-benzyl-2-[methoxy(methyl)amino]-2-oxo-ethyl]-N-methylcarbamate (8a). According to general method 1, 8a was obtained as a yellow oil (0.942 g, 86\%). ${ }^{1} \mathrm{H} \mathrm{NMR}\left(\mathrm{CDCl}_{3}, 300 \mathrm{MHz}\right), \delta(\mathrm{ppm})$ : indicates the presence of 2 conformers. 7.27-7.16 $(\mathrm{m}, 5 \mathrm{H})$; 5.64-5.07 [unresolved X part of ABX system, m, 1H); 3.64 and $3.61(2 \mathrm{~s}, 3 \mathrm{H}) ; 3.16$ and $3.19(2 \mathrm{~s}, 3 \mathrm{H}) ; 3.06-2.87$ [unresolved $\mathrm{AB}$ part of $\mathrm{ABX}$ system, m, 2H]; $2.85(\mathrm{~s}, 3 \mathrm{H}) ; 1.35$ and $1.23(2 \mathrm{~s}, 9 \mathrm{H}) .{ }^{13} \mathrm{C} \mathrm{NMR}\left(\mathrm{CDCl}_{3}, 75 \mathrm{MHz}\right), \delta(\mathrm{ppm})$ : indicates the presence of 2 conformers. 171.5, 155.6, 154.9, 138.0, 137.5, 129.4, 129.2, 128.4, 128.2, 126.4, 79.8, 61.3, 57.2, 54.7, 34.9, 30.2, 29.8, 28.2, 26.8. $\mathrm{MS}\left(\mathrm{ESI}^{+}\right): \mathrm{m} / \mathrm{z}=323.0[\mathrm{M}, \mathrm{H}]^{+}$found; $\mathrm{C}_{17} \mathrm{H}_{26} \mathrm{~N}_{2} \mathrm{O}_{4}$ calculated $\mathrm{m} / \mathrm{z}=323.2[\mathrm{M}, \mathrm{H}]^{+}$.

4.2.5. tert-butyl N-[(1S)-1-[(4-fluorophenyl)methyl]-2-[methoxy(methyl)amino]-2-oxoethyl]carbamate (9a). According to general method 1, 9a was obtained as a colorless oil (0.810 g, 70\%). ${ }^{1} \mathrm{H}$ NMR $\left(\mathrm{CDCl}_{3}, 300 \mathrm{MHz}\right), \delta(\mathrm{ppm})$ : 7.18-7.09 (m, 2H); 7.02-6.90 (m, 2H); 
5.28-5.17 (d, $J=12.1 \mathrm{~Hz}, 1 \mathrm{H}), 5.00-4.82$ (unresolved X part of ABX system, m, 1H); 3.67 (s, $3 \mathrm{H}) ; 3.16(\mathrm{~s}, 3 \mathrm{H}) ; 2.87$ [AB part of ABX system $(\mathrm{dd}, J=12.2$ and $6.3 \mathrm{~Hz}, 1 \mathrm{H})$ and $(\mathrm{dd}, J=$ 12.1 and $6.6 \mathrm{~Hz}, 1 \mathrm{H}), \Delta v=60 \mathrm{~Hz}] ; 1.38(\mathrm{~s}, 9 \mathrm{H}) .{ }^{13} \mathrm{C} \mathrm{NMR}\left(\mathrm{CDCl}_{3}, 75 \mathrm{MHz}\right), \delta(\mathrm{ppm}): 172.0$, 163.5, $160.2\left(\mathrm{~J}_{\mathrm{C}-\mathrm{F}}=234 \mathrm{~Hz}\right) ; 155.1,132.3,131.0,130.9,115.3,115.0,79.6,61.6,51.5,38.1$, 32.0, 28.3. MS $\left(\mathrm{ESI}^{+}\right): \mathrm{m} / \mathrm{z}=327.1[\mathrm{M}, \mathrm{H}]^{+}$found; $\mathrm{C}_{16} \mathrm{H}_{24} \mathrm{FN}_{2} \mathrm{O}_{4}$ calculated $\mathrm{m} / \mathrm{z}=$ $327.2[\mathrm{M}, \mathrm{H}]^{+}$.

4.2.6. tert-butyl (2S)-2-[methoxy(methyl)carbamoyl]piperidine-1-carboxylate (10a). According to general method 1, 10a was obtained as a yellow oil $(0.986 \mathrm{~g}, 83 \%) .{ }^{1} \mathrm{H}$ NMR $\left(\mathrm{CDCl}_{3}, 300 \mathrm{MHz}\right), \delta(\mathrm{ppm}): 5.18-4.87(\mathrm{~m}, 1 \mathrm{H}) ; 4.10-3.84(\mathrm{~m}, 1 \mathrm{H}) ; 3.76(\mathrm{~s}, 3 \mathrm{H}) ; 3.58-3.39$ $(\mathrm{m}, 1 \mathrm{H}) ; 3.18(\mathrm{~s}, 3 \mathrm{H}) ; 2.01(\mathrm{~d}, J=15.0 \mathrm{~Hz}, 1 \mathrm{H}) ; 1.75-1.57(\mathrm{~m}, 3 \mathrm{H}) ; 1.44(\mathrm{~s}, 9 \mathrm{H}) ; 1.34-1.20$ $(\mathrm{m}, 2 \mathrm{H}) .{ }^{13} \mathrm{C} \mathrm{NMR}\left(\mathrm{CDCl}_{3}, 75 \mathrm{MHz}\right), \delta(\mathrm{ppm}): 173.5,156.2,79.7,61.3,50.8,42.3,32.2,29.7$, 28.5, 26.5, 19.6. MS $\left(\mathrm{ESI}^{+}\right): \mathrm{m} / \mathrm{z}=273.1[\mathrm{M}, \mathrm{H}]^{+}$found; $\mathrm{C}_{13} \mathrm{H}_{25} \mathrm{~N}_{2} \mathrm{O}_{4}$ calculated $\mathrm{m} / \mathrm{z}=$ $273.2[\mathrm{M}, \mathrm{H}]^{+}$.

4.2.7. tert-butyl N-[(1S)-2-(methoxy(methyl)amino)-1-methyl-2-oxo-ethyl]carbamate (11a). According to general method 1, 11a was obtained as a yellow oil (0.566 g, 64\%). Analyses similar to literature description. ${ }^{51}$

4.2.8. tert-butyl N-[(1S)-1-[(4-tert-butoxyphenyl)methyl]-2-[methoxy(methyl)amino]-2-oxoethyl]carbamate (12a). According to general method 1, 12a was obtained as a yellow solid $(0.722 \mathrm{~g}, 76 \%)$. Analyses similar to literature description. ${ }^{52}$

4.2.9. tert-butyl $N$-[(1S)-2-[methoxy(methyl)amino]-1-methyl-2-oxo-ethyl]carbamate (13a). According to general method 1, 13a was obtained as a yellow solid (0.225 g, 48\%). Analyses similar to literature description. ${ }^{53}$

\subsection{Preparation of amine compounds $2 \mathrm{~b}-13 \mathrm{~b}$.}

4.3.1. General method 2. To a solution of Weinreb amide (1 eq.) in THF was added $\mathrm{LiAlH}_{4}$ ( 0.9 eq. of commercial solution $1 \mathrm{M}$ in THF) dropwise under $\mathrm{N}_{2}$ at $0^{\circ} \mathrm{C}$ and stirred for $1 \mathrm{~h}$ at $0^{\circ} \mathrm{C}$. Then saturated $\mathrm{KHSO}_{4}$ solution was added dropwise. THF was evaporated off. The resulting crude product was dissolved in $\mathrm{CH}_{2} \mathrm{Cl}_{2}$, washed twice with saturated $\mathrm{NaHCO}_{3}$ solution, twice with $1 \mathrm{M} \mathrm{HCl}$, once with brine. Organic layer was dried over $\mathrm{MgSO}_{4}$, filtered and concentrated in vacuo. No further purification was performed. To a solution of resulting aldehyde (1 eq) in $\mathrm{CH}_{2} \mathrm{Cl}_{2}$, benzylamine (1.2 eq) was added under $\mathrm{N}_{2}$. The mixture was stirred at room temperature for $30 \mathrm{~min}, \mathrm{NaBH}(\mathrm{OAc})_{3}(3 \mathrm{eq})$ was added portion wise (at least for 10 min). The mixture was stirred overnight, diluted with $\mathrm{CH}_{2} \mathrm{Cl}_{2}(3 \mathrm{~mL})$ and saturated $\mathrm{NaHCO}_{3}$ 
solution (3 mL) was added. The mixture was stirred for $10 \mathrm{~min}$. The organic layer was separated and the aqueous phase washed twice with $\mathrm{CH}_{2} \mathrm{Cl}_{2}(15 \mathrm{~mL})$. Combined organic layers were dried over $\mathrm{MgSO}_{4}$, filtered and evaporated in vacuo. Purification via flash chromatography was performed.

4.3.2. tert-butyl (3S)-3-[(benzylamino)methyl]-3,4-dihydro-1H-isoquinoline-2-carboxylate (2b). According to general method 2, 2b was obtained as a colorless oil $(0.55 \mathrm{~g}, 95 \%) .{ }^{1} \mathrm{H}$ NMR $\left(\mathrm{CDCl}_{3}, 300 \mathrm{MHz}\right), \delta(\mathrm{ppm})$ : 7.36-7.21 (m, 5H); 7.20-7.03 (m, 4H); $5.53(\mathrm{~s}, 1 \mathrm{H})$; 4.92$4.45(\mathrm{~m}, 2 \mathrm{H}) ; 4.22$ and $4.17(2 \mathrm{~s}, 1 \mathrm{H}) ; 3.85(\mathrm{dd}, J=19.5 \mathrm{~Hz}$ and $13.4 \mathrm{~Hz}, 2 \mathrm{H}) ; 2.93$ [AB part of $\mathrm{ABX}$ system (dd, $J=18.0$ and $6.0 \mathrm{~Hz}, 1 \mathrm{H})$ and $(\mathrm{dd}, J=15.0$ and $3.0 \mathrm{~Hz}, 1 \mathrm{H}), \Delta v=90 \mathrm{~Hz}]$; 2.72-2.58 (unresolved $\mathrm{AB}$ part of $\mathrm{ABX}$ system, m, $2 \mathrm{H}) ; 1.49$ (s, 9H). ${ }^{13} \mathrm{C} \mathrm{NMR}\left(\mathrm{CDCl}_{3}, 75\right.$ MHz), $\delta$ (ppm): 155.4, 140.5, 132.9, 129.1, 128.4, 128.0, 126.9, 126.6, 126.1, 79.9, 53.5, 50.1, 50.1, 48.3, 43.1, 31.1, 28.5. MS $\left(\mathrm{ESI}^{+}\right): \mathrm{m} / \mathrm{z}=353.3[\mathrm{M}, \mathrm{H}]^{+}$found; $\mathrm{C}_{22} \mathrm{H}_{29} \mathrm{~N}_{2} \mathrm{O}_{2}$ calculated $\mathrm{m} / \mathrm{z}=353.2[\mathrm{M}, \mathrm{H}]^{+}$.

4.3.3. tert-butyl (3S)-3-[[2-(2-pyridyl)ethylamino]methyl]-3,4-dihydro-1H-isoquinoline-2carboxylate (3b). According to general method 2, 3b was obtained as a light brown oil (0.386g, quantitative). ${ }^{1} \mathrm{H}$ NMR $\left(\mathrm{CDCl}_{3}, 300 \mathrm{MHz}\right), \delta(\mathrm{ppm}): 8.53(\mathrm{~s}, 1 \mathrm{H}) ; 7.69-6.78(\mathrm{~m}, 8 \mathrm{H})$; 5.01-4.63 (unresolved $\mathrm{AB}$ system, m, 2H); 4.39-4.13 (m, 1H); 3.32-2.64 (m, 8H); 1.45 (s, 9H). ${ }^{13} \mathrm{C} \mathrm{NMR}\left(\mathrm{CDCl}_{3}, 75 \mathrm{MHz}\right), \delta$ (ppm): 159.4, 136.8, 132.6, 132.0, 129.1, 126.7, 126.38, 123.5, 121.6, 80.5, 49.3, 48.6, 47.8, 31.4, 29.0, 28.6, 28.1, 27.7. MS $\left(\mathrm{ESI}^{+}\right): \mathrm{m} / \mathrm{z}=368.2$ $[\mathrm{M}, \mathrm{H}]^{+}$found; $\mathrm{C}_{22} \mathrm{H}_{30} \mathrm{~N}_{3} \mathrm{O}_{2}$ calculated $\mathrm{m} / \mathrm{z}=368.2[\mathrm{M}, \mathrm{H}]^{+}$.

4.3.4. tert-butyl (3S)-3-[(2-morpholinoethylamino)methyl]-3,4-dihydro-1H-isoquinoline-2carboxylate (4b). According to general method 2, 4b was obtained as a colorless oil ( 0.428 g, 99\%). ${ }^{1} \mathrm{H} \mathrm{NMR}\left(\mathrm{CDCl}_{3}, 300 \mathrm{MHz}\right), \delta(\mathrm{ppm})$ : 7.22-7.08 (m, 4H); 4.83-4.49 (unresolved AB system, m, 2H); 4.25 [X part of ABX system $\left(\mathrm{d}, J=18.0 \mathrm{~Hz}, 1 \mathrm{H}, \mathrm{CH}_{(\mathrm{b})}\right.$ ]; $3.70(\mathrm{ft}, J=3.0 \mathrm{~Hz}$, $4 \mathrm{H}) ; 2.92[\mathrm{AB}$ part of ABX system $(\mathrm{dd}, J=16.4$ and $6.7 \mathrm{~Hz}, 1 \mathrm{H})$ and $(\mathrm{d}, J=12.0 \mathrm{~Hz}, 1 \mathrm{H}), \Delta v$ $=96 \mathrm{~Hz}] ; 2.75-2.68(\mathrm{~m}, 2 \mathrm{H}) ; 2.44-2.42(\mathrm{~m}, 8 \mathrm{H}) ; 1.51(\mathrm{~s}, 9 \mathrm{H}) .{ }^{13} \mathrm{C} \mathrm{NMR}\left(\mathrm{CDCl}_{3}, 75 \mathrm{MHz}\right), \delta$ (ppm): 155.3, 133.1, 129.1, 126.6, 126.2, 79.9, 67.0, 58.3, 53.7, 53.4, 50.8, 45.9, 42.7, 31.1, 28.5. MS $\left(\mathrm{ESI}^{+}\right): \mathrm{m} / \mathrm{z}=376.1[\mathrm{M}, \mathrm{H}]^{+}$found $\mathrm{C}_{21} \mathrm{H}_{34} \mathrm{~N}_{3} \mathrm{O}_{3}$ calculated $\mathrm{m} / \mathrm{z}=376.2[\mathrm{M}, \mathrm{H}]^{+}$.

4.3.5. tert-butyl (3S)-3-[(4-phenylbutylamino)methyl]-3,4-dihydro-1H-isoquinoline-2carboxylate (5b). According to general method 2, 5b was obtained as a colorless oil (0.416 g, 92\%). ${ }^{1} \mathrm{H} \mathrm{NMR}\left(\mathrm{CDCl}_{3}, 300 \mathrm{MHz}\right), \delta$ (ppm): 8.19 (br s, 1H); 7.30-7.10 (m, 9H); 4.65 (m, $2 \mathrm{H}) ; 4.30$ [X part of ABX system $(\mathrm{d}, J=15.0 \mathrm{~Hz}, 1 \mathrm{H}$ ]; 3.12-2.59 (m, 8H); 1. 70-1.52 (m, $4 \mathrm{H}) ; 1.49$ (s, 9H). ${ }^{13} \mathrm{C} \mathrm{NMR}\left(\mathrm{CDCl}_{3}, 75 \mathrm{MHz}\right), \delta(\mathrm{ppm}): 156.0,154.9,141.8,132.8,132.4$, 128.9, 128.3, 127.0, 126.6, 126.1, 125.8, 80.8, 50.4, 49.3, 48.1, 47.8, 43.9, 42.7, 35.4, 31.7, 
28.4, 27.6, 27.0, 22.7. MS (ESI $\left.{ }^{+}\right): \mathrm{m} / \mathrm{z}=395.2[\mathrm{M}, \mathrm{H}]^{+}$found; $\mathrm{C}_{25} \mathrm{H}_{35} \mathrm{~N}_{2} \mathrm{O}_{2}$ calculated $\mathrm{m} / \mathrm{z}=$ $395.3[\mathrm{M}, \mathrm{H}]^{+}$.

4.3.6. tert-butyl (3S)-3-[(hexylamino)methyl]-3,4-dihydro-1H-isoquinoline-2-carboxylate (6b). According to general method 2, 6b was obtained as a colorless oil $(0.386 \mathrm{~g}, 97 \%)$. ${ }^{1} \mathrm{H}$ NMR $\left(\mathrm{CDCl}_{3}, 300 \mathrm{MHz}\right), \delta(\mathrm{ppm})$ : 7.23-7.10 (m, 4H); 4.88-4.13 (m, 2H); 4.37-4.15 (m, 1H); 3.09 (AB part of ABX system, dd, $J=16.2 \mathrm{~Hz}$ and $6.9 \mathrm{~Hz}, 1 \mathrm{H}) ; 2.85-2.67(\mathrm{~m}, 5 \mathrm{H}) ; 2.04$ (s, $3 \mathrm{H}) ; 1.50(\mathrm{~s}, 9 \mathrm{H}) ; 1.33-1.23(\mathrm{~m}, 6 \mathrm{H}) ; 0.87(\mathrm{t}, J=7.5 \mathrm{~Hz}, 3 \mathrm{H}) .{ }^{13} \mathrm{C} \mathrm{NMR}\left(\mathrm{CDCl}_{3}, 75 \mathrm{MHz}\right), \delta$ (ppm): 170.0, 133.0, 132.7, 128.9, 126.9, 126.4, 126.0, 80.5, 50.9, 50.4, 48.3, 39.7, 31.5, 29.6, 28.7, 28.2, 28.0, 22.5, 13.9. MS $\left(\mathrm{ESI}^{+}\right): \mathrm{m} / \mathrm{z}=347.2[\mathrm{M}, \mathrm{H}]^{+}$found; $\mathrm{C}_{21} \mathrm{H}_{35} \mathrm{~N}_{2} \mathrm{O}_{2}$ calculated $\mathrm{m} / \mathrm{z}=347.3[\mathrm{M}, \mathrm{H}]^{+}$.

4.3.7. tert-butyl N-[(1S)-1-benzyl-2-(benzylamino)ethyl]carbamate (7b). According to general method 2, 7b was obtained as a brown solid (0.498 g, 90\%). Analyses similar to literature description. ${ }^{54}$

4.3.8. tert-butyl N-[(1S)-1-benzyl-2-(benzylamino)ethyl]-N-methyl-carbamate $(\mathbf{8 b})$. According to general method 2, 8b was obtained as a light yellow oil $(0.120 \mathrm{~g}, 52 \%) .{ }^{1} \mathrm{H} \mathrm{NMR}\left(\mathrm{CDCl}_{3}\right.$, $300 \mathrm{MHz}), \delta(\mathrm{ppm})$ : indicates the presence of 2 conformers. 7.44-7.05 (m, 10H); 4.71-4.34 (unresolved X part of ABX system, m, 1H); 3.89 and 3.71 [AB part of ABX system $(\mathrm{d}, J=$ $13.1 \mathrm{~Hz}, 1 \mathrm{H})$ and $(\mathrm{m}, 1 \mathrm{H})] ; 2.93-2.55(\mathrm{~m}, 7 \mathrm{H}) ; 2.00($ br s, $1 \mathrm{H}) ; 1.38$ and $1.28(2 \mathrm{~s}, 9 \mathrm{H}) .{ }^{13} \mathrm{C}$ NMR ( $\left.\mathrm{CDCl}_{3}, 75 \mathrm{MHz}\right), \delta(\mathrm{ppm}):$ 156.3, 138.6, 129.0, 128.4, 128.2, 127.1, 126.6, 79.6, 55.6, 53.2, 50.1, 49.6, 36.9, 28.2. MS $\left(\mathrm{ESI}^{+}\right): \mathrm{m} / \mathrm{z}=355.1[\mathrm{M}, \mathrm{H}]^{+}$found; $\mathrm{C}_{22} \mathrm{H}_{30} \mathrm{~N}_{2} \mathrm{O}_{2}$ calculated $\mathrm{m} / \mathrm{z}=355.2[\mathrm{M}, \mathrm{H}]^{+}$.

4.3.9. tert-butyl N-[(1S)-1-[(benzylamino)methyl]-2-(4-fluorophenyl)ethyl]carbamate (9b). According to general method 2, 9b was obtained as a light yellow oil $(0.510 \mathrm{~g}, 70 \%) .{ }^{1} \mathrm{H}$ NMR ( $\left.\mathrm{CDCl}_{3}, 300 \mathrm{MHz}\right), \delta(\mathrm{ppm})$ : 7.38-7.22 (m, 5H); 7.16-7.08 (m, 2H); 7.01-6.89 (m, 2H); 4.74 (br s, 1H), 3.99-3.85 (unresolved X part of ABX system, m, 1H); 3.77 (AB system, $J=$ $12.4 \mathrm{~Hz}, \Delta v=24 \mathrm{~Hz}, 2 \mathrm{H}$ ); 2.90-2.71 (unresolved AB part of ABX system, m, 2H); 2.71-2.54 (unresolved $\mathrm{AB}$ part of $\mathrm{ABX}$ system, m, $2 \mathrm{H}) ; 2.10$ ( br s, $1 \mathrm{H}) ; 1.41(\mathrm{~s}, 9 \mathrm{H}) .{ }^{13} \mathrm{C} \mathrm{NMR}\left(\mathrm{CDCl}_{3}\right.$, $75 \mathrm{MHz}), \delta(\mathrm{ppm}): 163.2,160.0\left(J_{\mathrm{C}-\mathrm{F}}=242.2 \mathrm{~Hz}\right) ; 155.6,139.9,133.8,130.8,130.7,128.5$, 128.2, 127.1, 115.3, 115.0, 79.4, 53.7, 51.4, 51.2, 38.3, 28.4. MS $\left(\mathrm{ESI}^{+}\right): \mathrm{m} / \mathrm{z}=359.0[\mathrm{M}, \mathrm{H}]^{+}$ found; $\mathrm{C}_{21} \mathrm{H}_{28} \mathrm{FN}_{2} \mathrm{O}_{2}$ calculated $\mathrm{m} / \mathrm{z}=359.2[\mathrm{M}, \mathrm{H}]^{+}$.

4.3.10. tert-butyl (2S)-2-[(benzylamino)methyl]piperidine-1-carboxylate (10b). According to general method 2, 10b was obtained as a yellow oil $(0.453 \mathrm{~g}, 62 \%) .{ }^{1} \mathrm{H}$ NMR $\left(\mathrm{CDCl}_{3}, 300\right.$ $\mathrm{MHz}), \delta(\mathrm{ppm})$ : 7.37-7.20 (m, 5H); 4.45-4.32 (unresolved X part of ABX system, m, 1H); 4.02-3.87 (m, 1H); $3.83(\mathrm{AB}$ system, $\mathrm{d}, \mathrm{J}=12.0 \mathrm{~Hz}, \Delta v=24.2 \mathrm{~Hz}, 1 \mathrm{H}) ; 2.79$ [AB part of 
$\mathrm{ABX}$ system(dd, $\mathrm{J}=12.3$ and $3.1 \mathrm{~Hz}, 1 \mathrm{H})$ and $(\mathrm{dd}, \mathrm{J}=12.0$ and $6.6 \mathrm{~Hz}, 1 \mathrm{H}), \Delta v=81.2 \mathrm{~Hz})$; 2.73-2.69 (m, 1H); 1.76-1.53 (m, 6H); 1.44 (s, 9H). ${ }^{13} \mathrm{C} \mathrm{NMR}\left(\mathrm{CDCl}_{3}, 75 \mathrm{MHz}\right), \delta(\mathrm{ppm})$ : $155.1,140.4,128.3,128.0,126.9,124.8,79.4,53.4,49.9,48.0,39.3,28.5,26.7,25.4,19.3$. $\operatorname{MS}\left(\mathrm{ESI}^{+}\right): \mathrm{m} / \mathrm{z}=305.0[\mathrm{M}, \mathrm{H}]^{+}$found; $\mathrm{C}_{18} \mathrm{H}_{28} \mathrm{~N}_{2} \mathrm{O}_{2}$ calculated $\mathrm{m} / \mathrm{z}=305.2[\mathrm{M}, \mathrm{H}]^{+}$.

4.3.11. tert-butyl N-[2-(benzylamino)-1-methyl-ethyl]carbamate (11b). According to general method 2, 11b was obtained as a yellow oil (0.286 g, 19\%). Analyses similar to literature description. ${ }^{55}$

4.3.12. tert-butyl $N$-[(1S)-1-[(benzylamino)methyl]-2-(4-tert-butoxyphenyl)ethyl]carbamate $(\mathbf{1 2 b})$. According to general method 2, 12b was obtained as a yellow oil $(0.252 \mathrm{~g}, 58 \%) .{ }^{1} \mathrm{H}$ NMR ( $\left.\mathrm{CDCl}_{3}, 300 \mathrm{MHz}\right), \delta(\mathrm{ppm})$ : 7.33-7.20 (m, 5H); 7.14-6.98 (m, 2H); 6.91-6.82 (m, 2H); 4.98 (br s, 1H); 3.94-3.84 (unresolved X part of ABX system, m, 1H); 3.77 (AB system, $\mathrm{J}=$ 13.1 Hz, $\Delta v=26.8 \mathrm{~Hz}, 2 \mathrm{H}$ ); 3.12-2.91 (unresolved AB part of ABX system, m, 1H); 2.902.69 (unresolved $\mathrm{AB}$ part of $\mathrm{ABX}$ system, m, 3H); 1.41 and $1.32(2 \mathrm{~s}, 19 \mathrm{H}) .{ }^{13} \mathrm{C} \mathrm{NMR}\left(\mathrm{CDCl}_{3}\right.$, $75 \mathrm{MHz}), \delta(\mathrm{ppm}): 155.8,153.7,139.0,132.8,129.7,128.5,127.2,124.1,79.2,78.2$ 53.2, 51.0, 38.5, 28.8, 28.4. MS (ESI $)^{+}: \mathrm{m} / \mathrm{z}=413.1[\mathrm{M}, \mathrm{H}]^{+}$found; $\mathrm{C}_{25} \mathrm{H}_{37} \mathrm{~N}_{2} \mathrm{O}_{3}$ calculated $\mathrm{m} / \mathrm{z}=$ $413.3[\mathrm{M}, \mathrm{H}]^{+}$.

4.3.13. tert-butyl N-[(1S)-3-(benzylamino)-1-[(4-methoxyphenyl)methyl]-2-oxopropyl]carbamate $(\mathbf{1 3 b})$. According to general method 2, $\mathbf{1 3 b}$ was obtained as a yellow oil (0.032 g, 22\%). ${ }^{1} \mathrm{H} \mathrm{NMR}\left(\mathrm{CDCl}_{3}, 300 \mathrm{MHz}\right), \delta(\mathrm{ppm}): 7.31-7.15(\mathrm{~m}, 5 \mathrm{H}) ; 7.09$ (d, J = 8.6 Hz, $2 \mathrm{H}) ; 6.82(\mathrm{~d}, \mathrm{~J}=9.5 \mathrm{~Hz}, 2 \mathrm{H}) ; 4.74$ (br s, 1H); 3.89-3.78 (unresolved X part of ABX system, $\mathrm{m}, 1 \mathrm{H}) ; 3.77-3.68(\mathrm{~m}, 5 \mathrm{H}) ; 2.80-2.65$ (unresolved $\mathrm{AB}$ part of ABX system, $\mathrm{m}, 2 \mathrm{H}) ; 2.63-2.57$ (unresolved $\mathrm{AB}$ part of $\mathrm{ABX}$ system, m, $2 \mathrm{H}) ; 1.75-1.66(\mathrm{~m}, 1 \mathrm{H}, \mathrm{NH}) ; 1.43(\mathrm{~s}, 9 \mathrm{H}) .{ }^{13} \mathrm{C} \mathrm{NMR}$ $\left(\mathrm{CDCl}_{3}, 75 \mathrm{MHz}\right), \delta(\mathrm{ppm}): 158.2,155.7,140.2,130.3,130.1,128.4,128.2,127.0,113.8$, 79.8, 55.2, 53.8, 51.33, 42.9, 38.2, 28.4. MS $\left(\mathrm{ESI}^{+}\right): \mathrm{m} / \mathrm{z}=371.2[\mathrm{M}, \mathrm{H}]^{+}$found $\mathrm{C}_{22} \mathrm{H}_{31} \mathrm{~N}_{2} \mathrm{O}_{3}$ calculated $\mathrm{m} / \mathrm{z}=371.2[\mathrm{M}, \mathrm{H}]^{+}$.

\subsection{Preparation of guanidine compounds 2-13.}

4.4.1. General method 3. To a solution of appropriate secondary amine (1 eq) in EtOH (1.6 $\mathrm{mL} / \mathrm{mmol}$ of amine), $\mathrm{NaHCO}_{3}(3 \mathrm{eq})$ and $\mathrm{BrCN}$ (1.1 eq) were added. The mixture was stirred at room temperature for $5 \mathrm{~h}$. The mixture was diluted with $\mathrm{H}_{2} \mathrm{O}$ and extracted twice with $\mathrm{CH}_{2} \mathrm{Cl}_{2}$. Combined organic layers were dried under $\mathrm{MgSO}_{4}$. The solution was filtered and evaporated in vacuo. No further purification was performed unless specified. The nitrile compound (1 eq) was dissolved in $3 \mathrm{M} \mathrm{HCl} /$ dioxane $(0.08 \mathrm{M})$ and stirred at room temperature 
overnight. Dioxane was evaporated in vacuo. Purification via flash chromatography was performed.

4.4.2.

(10aS)-2-benzyl-1,5,10,10a-tetrahydroimidazo[1,5-b]isoquinolin-3-imine

monohydrochloride (2). According to general method 2, 2 was obtained (chromatography, $\mathrm{CH}_{2} \mathrm{Cl}_{2} /$ methanol 94/6) as a white powder $(0.13 \mathrm{~g}, 46 \%) .{ }^{1} \mathrm{H}$ NMR $\left(\mathrm{CD}_{3} \mathrm{OD}, 300 \mathrm{MHz}\right), \delta$ (ppm): 7.41-7.36 (m, 5H); 7.26-7.18 (m, 4H); 4.72-4.54 (m, 4H); 4.11-4.01 (m, 1H); 3.61 [AB part of ABX system (t, $J=9.0 \mathrm{~Hz}, 1 \mathrm{H})$ and $(\mathrm{t}, J=6.0 \mathrm{~Hz}, 1 \mathrm{H}), \Delta v=144 \mathrm{~Hz}] ; 2.95[\mathrm{AB}$ part of ABX system (dd, $J=18.0$ and $9.0 \mathrm{~Hz}, 1 \mathrm{H})$ and $(\mathrm{dd}, J=15.0$ and $9.0 \mathrm{~Hz}, 1 \mathrm{H}), \Delta v=72$ $\mathrm{Hz}] .{ }^{13} \mathrm{C}$ NMR $\left(\mathrm{CD}_{3} \mathrm{OD}, 75 \mathrm{MHz}\right), \delta(\mathrm{ppm}): 156.7,134.4,132.0,129.9,129.1,128.8,128.1$, 127.7, 127.0, 126.8, 126.2, 53.2, 51.7, 48.5, 43.9, 33.4. HRMS $\left(\mathrm{ESI}^{+}\right): \mathrm{m} / \mathrm{z}=278.16548$ $[\mathrm{M}, \mathrm{H}]^{+}$found; $\mathrm{C}_{18} \mathrm{H}_{19} \mathrm{~N}_{3}$ calculated $\mathrm{m} / \mathrm{z}=278.16517[\mathrm{M}, \mathrm{H}]^{+} . \mathrm{Mp}: 198.5^{\circ} \mathrm{C} \cdot \alpha_{\mathrm{D}}\left(20^{\circ} \mathrm{C}\right.$, $\left.\mathrm{CH}_{3} \mathrm{OH}\right)=-0.548^{\circ}(0.500 \mathrm{mg} / \mathrm{mL}) . \mathrm{IR}, v\left(\mathrm{~cm}^{-1}\right): 3089,1660(\mathrm{C}=\mathrm{N})$. HPLC: $\mathrm{C}_{4}$ column: $\mathrm{t}_{\mathrm{R}}=$ 11.7 min, purity $>99 \% \mathrm{C}_{18}$ column: $\mathrm{t}_{\mathrm{R}}=20.5 \mathrm{~min}$, purity $>99 \%$.

4.4.3. (10aS)-2-[2-(2-pyridyl)ethyl]-1,5,10,10a-tetrahydroimidazo[1,5-b]isoquinolin-3-imine dihydrochloride (3). According to general method 2, $\mathbf{3}$ was obtained (chromatography, $\mathrm{CH}_{2} \mathrm{Cl}_{2} /$ methanol 90/10) as a white powder $(0.10 \mathrm{~g}, 67 \%) .{ }^{1} \mathrm{H}$ NMR $\left(\mathrm{CD}_{3} \mathrm{OD}, 300 \mathrm{MHz}\right), \delta$ (ppm): $8.84(\mathrm{~d}, \mathrm{~J}=6.0 \mathrm{~Hz}, 1 \mathrm{H}) ; 8.64(\mathrm{t}, \mathrm{J}=9.0 \mathrm{~Hz}, 1 \mathrm{H}) ; 8.23(\mathrm{~d}, J=6.0 \mathrm{~Hz}, 1 \mathrm{H}) ; 8.04$ (t, $J=$ $9.0 \mathrm{~Hz}, 1 \mathrm{H}) ; 7.23$ (s, 4H); 4.67 (AB system, $J=15.0 \mathrm{~Hz}, \Delta v=75 \mathrm{~Hz}, 2 \mathrm{H}]$; 4.15-3.91 (m, 4H); $3.63[\mathrm{AB}$ part of ABX system $(\mathrm{t}, J=9.0 \mathrm{~Hz}, 1 \mathrm{H}) \Delta v=114 \mathrm{~Hz}] ; 3.56(\mathrm{t}, J=8.0 \mathrm{~Hz}, 2 \mathrm{H}) ; 2.99$ [AB part of ABX system $(\mathrm{d}, J=15.0 \mathrm{~Hz}, 1 \mathrm{H}]$ and $(\mathrm{t}, J=9.0 \mathrm{~Hz}, 1 \mathrm{H}), \Delta v=51 \mathrm{~Hz}) .{ }^{13} \mathrm{C} \mathrm{NMR}$ $\left(\mathrm{CD}_{3} \mathrm{OD}, 75 \mathrm{MHz}\right), \delta(\mathrm{ppm}): 156.6,152.9,147.1,141.4,131.9,129.7,129.1,128.1,127.0$, 126.8, 126.1, 125.7, 53.4, 52.6, 43.8, 44.2, 33.4. HRMS $\left(\mathrm{ESI}^{+}\right): \mathrm{m} / \mathrm{z}=293.17595[\mathrm{M}, \mathrm{H}]^{+}$ found; $\mathrm{C}_{18} \mathrm{H}_{20} \mathrm{~N}_{4}$ calculated $\mathrm{m} / \mathrm{z}=293.17607[\mathrm{M}, \mathrm{H}]^{+}$. Mp: $123.8^{\circ} \mathrm{C} . \alpha_{\mathrm{D}}\left(20^{\circ} \mathrm{C}, \mathrm{CH}_{3} \mathrm{OH}\right)=-$ $0.449^{\circ}(0.500 \mathrm{mg} / \mathrm{mL}) . \mathrm{IR}, v\left(\mathrm{~cm}^{-1}\right): 3039,1668(\mathrm{C}=\mathrm{N})$. HPLC: $\mathrm{C}_{4}$ column: $\mathrm{t}_{\mathrm{R}}=6.7 \mathrm{~min}$, purity $>99 \% \mathrm{C}_{18}$ column: $\mathrm{t}_{\mathrm{R}}=12.9 \mathrm{~min}$, purity $98 \%$.

4.4.4. (10aS)-2-(2-morpholinoethyl)-1,5,10,10a-tetrahydroimidazo[1,5-b]isoquinolin-3-imine dihydrochloride (4). According to general method 2, 4 was obtained (chromatography, $\mathrm{CH}_{2} \mathrm{Cl}_{2}$ /methanol 90/10) as a brown oil (0.282 $\left.\mathrm{g}, 69 \%\right) .{ }^{1} \mathrm{H} \mathrm{NMR}\left(\mathrm{CD}_{3} \mathrm{OD}, 300 \mathrm{MHz}\right), \delta$ (ppm): 7.34-7.18 (m, 4H); 4.66 (AB system, $J=16.0 \mathrm{~Hz}, \Delta v=70 \mathrm{~Hz}, 2 \mathrm{H})$; 4.17-3.99 (m, $1 \mathrm{H}) ; 3.71(\mathrm{t}, J=4.6 \mathrm{~Hz}, 4 \mathrm{H}) ; 3.67-3.48(\mathrm{~m}, 4 \mathrm{H}) ; 3.03$ [AB part of ABX system $(\mathrm{dd}, J=15.0$ and $3.7 \mathrm{~Hz}, 1 \mathrm{H})$ and $(\mathrm{dd}, J=15.4$ and $10.3 \mathrm{~Hz}, 1 \mathrm{H}), \Delta v=51 \mathrm{~Hz}] ; 2.69(\mathrm{t}, J=5.8 \mathrm{~Hz}, 2 \mathrm{H})$; $2.60(\mathrm{t}, J=4.5 \mathrm{~Hz}, 4 \mathrm{H}) .{ }^{13} \mathrm{C} \mathrm{NMR}\left(\mathrm{CD}_{3} \mathrm{OD}, 75 \mathrm{MHz}\right), \delta(\mathrm{ppm}): 157.4,132.0,129.9,129.1$, 127.0, 126.8, 126.0, 66.4, 55.7, 53.5, 53.2, 43.7, 42.3, 30.7. HRMS $\left(\mathrm{ESI}^{+}\right): \mathrm{m} / \mathrm{z}=301.20265$ 
$[\mathrm{M}, \mathrm{H}]^{+}$found; $\mathrm{C}_{17} \mathrm{H}_{25} \mathrm{~N}_{4} \mathrm{O}$ calculated $\mathrm{m} / \mathrm{z}=301.20229[\mathrm{M}, \mathrm{H}]^{+}$. HPLC: $\mathrm{C}_{4}$ column: $\mathrm{t}_{\mathrm{R}}=12.3$ min, purity $>94 \% \mathrm{C}_{18}$ column: $\mathrm{t}_{\mathrm{R}}=4.7 \mathrm{~min}$, purity $97 \%$.

4.4.5. (10aS)-2-(4-phenylbutyl)-1,5,10,10a-tetrahydroimidazo[1,5-b]isoquinolin-3-imine hydrochloride (5). According to general method 2, 5 was obtained (chromatography, $\mathrm{CH}_{2} \mathrm{Cl}_{2}$ /methanol 94/6) as a light brown oil (0.206 g, 82\%). ${ }^{1} \mathrm{H} \mathrm{NMR}\left(\mathrm{CD}_{3} \mathrm{OD}, 300 \mathrm{MHz}\right), \delta$ (ppm): 7.29-7.13 (m, 9H); 4.62 ([AB system (dd, $J=18.0 \mathrm{~Hz}, \Delta v=81 \mathrm{~Hz}, 2 \mathrm{H}) ; 4.03-3.97$ [unresolved X part of ABX system $(\mathrm{m}, 1 \mathrm{H})$ ]; 3.87 and 3.46-3.32 [AB part of ABX system (t, $J=9.0 \mathrm{~Hz}, 1 \mathrm{H})$ and $(\mathrm{m}, 1 \mathrm{H}), \Delta v=144 \mathrm{~Hz}] ; 3.46-3.39(\mathrm{~m}, 2 \mathrm{H}) ; 2.95$ [AB part of ABX system $(\mathrm{dd}, J=15.0$ and $3.0 \mathrm{~Hz}, 1 \mathrm{H})$ and $(\mathrm{dd}, J=15.0$ and $9.0 \mathrm{~Hz}, 1 \mathrm{H}), \Delta v=72 \mathrm{~Hz}$; 2.69 (t, $J=9.0$ $\mathrm{Hz}, 2 \mathrm{H}) ; 1.83-1.60(\mathrm{~m}, 4 \mathrm{H}) .{ }^{13} \mathrm{C}$ NMR (CD $\left.3 \mathrm{OD}, 75 \mathrm{MHz}\right), \delta(\mathrm{ppm}): 156.6,141.8,132.0$, 129.9, 129.7, 128.8, 128.0, 127.3, 126.9, 126.8, 126.1, 125.5, 124.8, 53.1, 51.9, 45.4, 43.3, 35.0, 33.3, 28.0, 26.1. HRMS $\left(\mathrm{ESI}^{+}\right): \mathrm{m} / \mathrm{z}=320.21259[\mathrm{M}, \mathrm{H}]^{+}$found; $\mathrm{C}_{21} \mathrm{H}_{26} \mathrm{~N}_{3}$ calculated $\mathrm{m} / \mathrm{z}=320.21212[\mathrm{M}, \mathrm{H}]^{+} . \alpha_{\mathrm{D}}\left(20^{\circ} \mathrm{C}, \mathrm{CH}_{3} \mathrm{OH}\right)=-0.499^{\circ}(0.500 \mathrm{mg} / \mathrm{mL}) . \mathrm{IR}, v\left(\mathrm{~cm}^{-1}\right): 2929$, $1664(\mathrm{C}=\mathrm{N})$. HPLC: $\mathrm{C}_{4}$ column: $\mathrm{t}_{\mathrm{R}}=12.7 \mathrm{~min}$, purity $98 \% \mathrm{C}_{18}$ column: $\mathrm{t}_{\mathrm{R}}=23.7 \mathrm{~min}$, purity $98 \%$.

4.4.6. tert-butyl (3S)-3-[(hexylamino)methyl]-3,4-dihydro-1H-isoquinoline-2-carboxylate (6). According to general method 2, 6 was obtained (chromatography, $\mathrm{CH}_{2} \mathrm{Cl}_{2} /$ methanol 85/15) as an orange oil (228 mg, 88\%). ${ }^{1} \mathrm{H}$ NMR (CD $\left.{ }_{3} \mathrm{OD}, 300 \mathrm{MHz}\right), \delta$ (ppm): 7.29-7.14 (m, 4H); 4.68 (AB system, $J=15.7 \mathrm{~Hz}, \Delta v=90.6 \mathrm{~Hz}, 2 \mathrm{H})$; 4.03-3.94 (m, 2H); 3.64-3.32 (m, 3H); 2.97 [AB part of ABX system (dd, $J=15.5$ and $2.7 \mathrm{~Hz}, 1 \mathrm{H})$ and $(\mathrm{dd}, J=15.5$ and $10.0 \mathrm{~Hz}, 1 \mathrm{H}), \Delta v=$ $87.7 \mathrm{~Hz}$; 1.66 (quin, $J=6.9 \mathrm{~Hz}, 2 \mathrm{H}) ; 1.49-1.31(\mathrm{~m}, 6 \mathrm{H}) ; 0.93(\mathrm{t}, J=6.2 \mathrm{~Hz}, 3 \mathrm{H}) .{ }^{13} \mathrm{C} \mathrm{NMR}$ $\left(\mathrm{CD}_{3} \mathrm{OD}, 75 \mathrm{MHz}\right), \delta$ (ppm): 156.6, 132.1, 130.1, 129.1, 127.0, 126.8, 126.2, 53.2, 52.0, 44.9, 43.9, 33.4, 31.3, 26.6, 25.9, 22.3, 13.1. HRMS $\left(\mathrm{ESI}^{+}\right): \mathrm{m} / \mathrm{z}=272.21249[\mathrm{M}, \mathrm{H}]^{+}$found; $\mathrm{C}_{17} \mathrm{H}_{26} \mathrm{~N}_{3}$ calculated $\mathrm{m} / \mathrm{z}=272.21212[\mathrm{M}, \mathrm{H}]^{+}$. HPLC: $\mathrm{C}_{4}$ column: $\mathrm{t}_{\mathrm{R}}=3.3 \mathrm{~min}$, purity $98 \%$ $\mathrm{C}_{18}$ column: $\mathrm{t}_{\mathrm{R}}=26.9 \mathrm{~min}$, purity $97 \%$.

4.4.7. (4S)-1,4-dibenzylimidazolidin-2-imine hydrochloride (7). According to general method 2, 7 was obtained (chromatography, $\mathrm{CH}_{2} \mathrm{Cl}_{2} /$ methanol 95/5) as a white powder (19 $\mathrm{mg}, 27 \%$ ). ${ }^{1} \mathrm{H}$ NMR (CD $\left.3 \mathrm{OD}, 300 \mathrm{MHz}\right), \delta(\mathrm{ppm}): 7.38-7.22(\mathrm{~m}, 6 \mathrm{H}) ; 7.21-7.10(\mathrm{~m}, 4 \mathrm{H}) ; 4.35$ (dd, $J=$ 28.9 and $13.5 \mathrm{~Hz}, 2 \mathrm{H})$; 4.29-4.21 (unresolved X part of ABX system, m, 1H); 3.61 and 3.333.27 [AB part of ABX system $(\mathrm{ft}, J=9.6 \mathrm{~Hz}, 1 \mathrm{H})$ and $(\mathrm{m}, 1 \mathrm{H}), \Delta v=93 \mathrm{~Hz}] ; 2.87(\mathrm{~d}, J=5.9$ $\mathrm{Hz}, 2 \mathrm{H}) .{ }^{13} \mathrm{C} \mathrm{NMR}\left(\mathrm{CD}_{3} \mathrm{OD}, 75 \mathrm{MHz}\right), \delta$ (ppm): 157.9, 135.7, 134.2, 129.2, 128.8, 128.4, 127.9, 127.4, 126.7, 53.8, 51.1, 48.5, 39.9. HRMS $\left(\mathrm{ESI}^{+}\right): \mathrm{m} / \mathrm{z}=266.16529[\mathrm{M}, \mathrm{H}]^{+}$found; $\mathrm{C}_{17} \mathrm{H}_{20} \mathrm{~N}_{3}$ calculated $\mathrm{m} / \mathrm{z}=266.16517[\mathrm{M}, \mathrm{H}]^{+} . \mathrm{Mp}: 196.1^{\circ} \mathrm{C} . \alpha_{\mathrm{D}}\left(20^{\circ} \mathrm{C}, \mathrm{CH}_{3} \mathrm{OH}\right)=-0.006^{\circ}$ 
$(0.500 \mathrm{mg} / \mathrm{mL}) . \mathrm{IR}, v\left(\mathrm{~cm}^{-1}\right): 3060,1668(\mathrm{C}=\mathrm{N})$. HPLC: $\mathrm{C}_{4}$ column: $\mathrm{t}_{\mathrm{R}}=13.1 \mathrm{~min}$, purity > $99 \% \mathrm{C}_{18}$ column: $\mathrm{t}_{\mathrm{R}}=24.7 \mathrm{~min}$, purity $>99 \%$.

4.4.8. (4S)-1,4-dibenzyl-3-methyl-imidazolidin-2-imine hydrochloride (8). According to general method 2, 8 was obtained (chromatography, $\mathrm{CH}_{2} \mathrm{Cl}_{2} /$ methanol 95/5) a white powder (14 mg, 67\%). ${ }^{1} \mathrm{H}$ NMR (CD $\left.3 \mathrm{OD}, 300 \mathrm{MHz}\right), \delta(\mathrm{ppm})$ : 7.39-7.23 (m, 6H); 7.17-7.04 (m, 4H); 4.39 (AB system, $J=15.7 \mathrm{~Hz}, \Delta v=38.9 \mathrm{~Hz}, 2 \mathrm{H}$ ); 4.23-4.11 (unresolved X part of ABX system, $\mathrm{m}, 1 \mathrm{H}) ; 3.37$ [AB part of ABX system $(\mathrm{t}, J=9.7 \mathrm{~Hz}, 1 \mathrm{H})$ and $(\mathrm{dd}, J=9.9$ and $5.7 \mathrm{~Hz}$, $1 \mathrm{H}), \Delta v=91.7 \mathrm{~Hz}] ; 3.10(\mathrm{~s}, 3 \mathrm{H}) ; 2.94[\mathrm{AB}$ part of ABX system $(\mathrm{dd}, J=13.9$ and $4.4 \mathrm{~Hz}, 1 \mathrm{H})$ and $(\mathrm{dd}, J=7.1$ and $6.8 \mathrm{~Hz}, 1 \mathrm{H}), \Delta v=61.9 \mathrm{~Hz}] .{ }^{13} \mathrm{C} \mathrm{NMR}\left(\mathrm{CD}_{3} \mathrm{OD}, 75 \mathrm{MHz}\right), \delta(\mathrm{ppm})$ : $157.4,135.3,134.2,129.2,128.7,128.5,127.9,127.3,126.9,59.8,49.4,48.0\left(\mathrm{CH}_{2(\mathrm{~d})}\right) ; 36.8$ $\left(\mathrm{CH}_{2(\mathrm{a})}\right) ; 30.2\left(\mathrm{CH}_{3(1)}\right)$. HRMS $\left(\mathrm{ESI}^{+}\right): \mathrm{m} / \mathrm{z}=280.18080[\mathrm{M}, \mathrm{H}]^{+}$found; $\mathrm{C}_{18} \mathrm{H}_{22} \mathrm{~N}_{3}$ calculated $\mathrm{m} / \mathrm{z}=280.18082[\mathrm{M}, \mathrm{H}]^{+} . \mathrm{Mp}: 244.5^{\circ} \mathrm{C} . \alpha_{\mathrm{D}}\left(20^{\circ} \mathrm{C}, \mathrm{CH}_{3} \mathrm{OH}\right)=-0.098^{\circ}(0.500 \mathrm{mg} / \mathrm{mL}) . \mathrm{IR}, v$ $\left(\mathrm{cm}^{-1}\right): 3024,1664(\mathrm{C}=\mathrm{N})$. HPLC: $\mathrm{C}_{4}$ column: $\mathrm{t}_{\mathrm{R}}=10.1 \mathrm{~min}$, purity $>99 \% \mathrm{C}_{18}$ column: $\mathrm{t}_{\mathrm{R}}=$ 4.5 min, purity $>99 \%$.

4.4.9. (4S)-1-benzyl-4-[(4-fluorophenyl)methyl]imidazolidin-2-imine hydrochloride (9). According to general method 2, 9 was obtained (chromatography, $\mathrm{CH}_{2} \mathrm{Cl}_{2} /$ methanol 90/10) a white powder (217 mg, 90\%). ${ }^{1} \mathrm{H}$ NMR ( $\left.\mathrm{CD}_{3} \mathrm{OD}, 300 \mathrm{MHz}\right), \delta(\mathrm{ppm}): 7.41-7.28(\mathrm{~m}, 3 \mathrm{H})$; 7.26-7.17 (m, 2H); 7.17-7.09 (m, 2H); 7.06-6.95 (m, 2H); 4.44 [AB system, $J=16.1 \mathrm{~Hz}, \Delta v=$ $41 \mathrm{~Hz}, 2 \mathrm{H}$ ); 4.32-4.19 (unresolved $\mathrm{X}$ part of $\mathrm{ABX}$ system, m, 1H); 3.62 and 3.34-3.24 [unresolved $\mathrm{AB}$ part of $\mathrm{ABX} \operatorname{system}(\mathrm{t}, J=11.2 \mathrm{~Hz}, 1 \mathrm{H})$ and $(\mathrm{m}, 1 \mathrm{H}), \Delta v=108 \mathrm{~Hz}$ ]; 2.942.77 (unresolved $\mathrm{AB}$ part of $\mathrm{ABX}$ system, m, 2H). ${ }^{13} \mathrm{C} \mathrm{NMR}\left(\mathrm{CD}_{3} \mathrm{OD}, 75 \mathrm{MHz}\right), \delta(\mathrm{ppm})$ : 163.7, $160.4\left(\mathrm{~J}_{\mathrm{C}-\mathrm{F}}=242.1 \mathrm{~Hz}\right) ; 157.9,134.2,131.6,131.1,131.0,128.7 ; 127.9,127.5,115.2$, 114.9, 53.7, 50.9, 48.5, 38.8. HRMS $\left(\mathrm{ESI}^{+}\right): \mathrm{m} / \mathrm{z}=284.15576[\mathrm{M}, \mathrm{H}]^{+}$found; $\mathrm{C}_{17} \mathrm{H}_{19} \mathrm{FN}_{3}$ calculated $\mathrm{m} / \mathrm{z}=284.15575[\mathrm{M}, \mathrm{H}]^{+} . \mathrm{Mp}: 244.5^{\circ} \mathrm{C} . \alpha_{\mathrm{D}}\left(20^{\circ} \mathrm{C}, \mathrm{CH}_{3} \mathrm{OH}\right)=-0.072^{\circ}(0.500$ $\mathrm{mg} / \mathrm{mL}$ ). HPLC: $\mathrm{C}_{4}$ column: $\mathrm{t}_{\mathrm{R}}=11.0 \mathrm{~min}$, purity $>99 \% \mathrm{C}_{18}$ column: $\mathrm{t}_{\mathrm{R}}=19.5 \mathrm{~min}$, purity $>$ $99 \%$.

4.4.10. (8aS)-2-benzyl-1,5,6,7,8,8a-hexahydroimidazo[1,5-a]pyridin-3-imine hydrochloride (10). According to general method 2, 10 was obtained (chromatography, $\mathrm{CH}_{2} \mathrm{Cl}_{2} /$ methanol 90/10) a white powder (130 mg, 29\%). ${ }^{1} \mathrm{H}$ NMR (CD $\left.{ }_{3} \mathrm{OD}, 300 \mathrm{MHz}\right), \delta(\mathrm{ppm}):$ 7.47-7.28 (m, $5 \mathrm{H}) ; 4.59(\mathrm{AB}$ system, $\mathrm{d}, \mathrm{J}=15.1 \mathrm{~Hz}, \Delta v=18.7 \mathrm{~Hz}, 1 \mathrm{H}] ; 3.92-3.88(\mathrm{~m}, 1 \mathrm{H}) ; 3.51$ [unresolved $\mathrm{AB}$ part of $\mathrm{ABX}$ system $(\mathrm{dd}, \mathrm{J}=12.3$ and $9.0 \mathrm{~Hz}, 1 \mathrm{H})$ and $(\mathrm{dd}, \mathrm{J}=15.3$ and 9.2 $\mathrm{Hz}, 1 \mathrm{H}), \Delta \mathrm{v}=246 \mathrm{~Hz}] ; 3.87-3.73(\mathrm{~m}, 1 \mathrm{H}) ; 3.08(\mathrm{dd}, \mathrm{J}=9.0$ and $3.1 \mathrm{~Hz}, 1 \mathrm{H}) ; 1.91-1.77(\mathrm{~m}$, $2 \mathrm{H}) ; 1.58-1.30(\mathrm{~m}, 4 \mathrm{H}) .{ }^{13} \mathrm{C} \mathrm{NMR}\left(\mathrm{CD}_{3} \mathrm{OD}, 75 \mathrm{MHz}\right), \delta(\mathrm{ppm}): 156.0,134.4,128.7,128.0$; 127.5, 59.5, 51.5, 47.8, 42.3, 29.7, 24.0, 22.2. HRMS $\left(\mathrm{ESI}^{+}\right): \mathrm{m} / \mathrm{z}=230.16490[\mathrm{M}, \mathrm{H}]^{+}$found; 
$\mathrm{C}_{14} \mathrm{H}_{20} \mathrm{~N}_{3}$ calculated $\mathrm{m} / \mathrm{z}=230.16517[\mathrm{M}, \mathrm{H}]^{+} . \mathrm{Mp}: 188.2^{\circ} \mathrm{C} . \alpha_{\mathrm{D}}\left(20^{\circ} \mathrm{C}, \mathrm{CH}_{3} \mathrm{OH}\right)=+10.6^{\circ}$ $(0.500 \mathrm{mg} / \mathrm{mL}) . \mathrm{IR}, v\left(\mathrm{~cm}^{-1}\right): 2941,1660(\mathrm{C}=\mathrm{N})$. HPLC: $\mathrm{C}_{4}$ column: $\mathrm{t}_{\mathrm{R}}=9.0 \mathrm{~min}$, purity $98 \%$ $\mathrm{C}_{18}$ column: $\mathrm{t}_{\mathrm{R}}=16.6$ min, purity $>99 \%$.

4.4.11. (4S)-1-benzyl-4-methyl-imidazolidin-2-imine hydrochloride (11). According to general method 2, 11 was obtained (chromatography, $\mathrm{CH}_{2} \mathrm{Cl}_{2} /$ methanol 90/10) a white powder (42 $\mathrm{mg}, 53 \%) .{ }^{1} \mathrm{H}$ NMR $\left(\mathrm{CD}_{3} \mathrm{OD}, 300 \mathrm{MHz}\right), \delta$ (ppm): 7.48-7.27 (m, 5H); 4.59 (br s, 1H); 4.42 (br s, 2H); 4.12-3.99 (unresolved X part of ABX system, m, 1H); 3.71 and 3.14 [AB part of ABX system (dd, $J=18.9$ and $9.5 \mathrm{~Hz}, 1 \mathrm{H})$ and $(\mathrm{dd}, J=9.6$ and $6.7 \mathrm{~Hz}, 1 \mathrm{H}) \Delta v=179.9 \mathrm{~Hz}) ; 1.25$ $(\mathrm{d}, J=6.0 \mathrm{~Hz}, 3 \mathrm{H}) .{ }^{13} \mathrm{C} \mathrm{NMR}\left(\mathrm{CD}_{3} \mathrm{OD}, 75 \mathrm{MHz}\right), \delta(\mathrm{ppm}): 158.0,134.5,128.8,127.9,127.5$, 53.6, 48.9, 19.5. HRMS $\left(\mathrm{ESI}^{+}\right): \mathrm{m} / \mathrm{z}=190.13416[\mathrm{M}, \mathrm{H}]^{+}$found; $\mathrm{C}_{11} \mathrm{H}_{16} \mathrm{~N}_{3}$ calculated $\mathrm{m} / \mathrm{z}=$ 190.13387 [M,H] ${ }^{+} . \mathrm{Mp}: 194.9^{\circ} \mathrm{C} . \alpha_{\mathrm{D}}\left(20^{\circ} \mathrm{C}, \mathrm{CH}_{3} \mathrm{OH}\right)=-0.045^{\circ}(0.500 \mathrm{mg} / \mathrm{mL}) . \mathrm{IR}, v\left(\mathrm{~cm}^{-1}\right)$ : 3055, $1667(\mathrm{C}=\mathrm{N})$. HPLC: $\mathrm{C}_{4}$ column: $\mathrm{t}_{\mathrm{R}}=7.3 \mathrm{~min}$, purity $98 \% \mathrm{C}_{18}$ column: $\mathrm{t}_{\mathrm{R}}=8.0 \mathrm{~min}$, purity $>99 \%$.

4.4.12. 4-[[(4S)-1-benzyl-2-imino-imidazolidin-4-yl]methyl]phenol hydrochloride According to general method 2, 12 was obtained (chromatography, $\mathrm{CH}_{2} \mathrm{Cl}_{2} /$ methanol 85/15) a brown solid (53 mg, 73\%). ${ }^{1} \mathrm{H}$ NMR (CD $\left.3 \mathrm{OD}, 300 \mathrm{MHz}\right), \delta(\mathrm{ppm}): 7.33(\mathrm{~m}, 3 \mathrm{H}) ; 7.06(\mathrm{~m}$, $2 \mathrm{H}) ; 6.98(\mathrm{~d}, J=8.5 \mathrm{~Hz}, 2 \mathrm{H}) ; 6.72(\mathrm{~d}, J=8.5 \mathrm{~Hz}, 2 \mathrm{H}) ; 4.45$ (AB system, $J=15.8 \mathrm{~Hz}, 2 \mathrm{H}, \Delta v$ $=42.9 \mathrm{~Hz}$ ); 4.20 (unresolved $\mathrm{X}$ part of ABX system, m, 1H); 3.59 and 3.33-3.27 [AB part of ABX system $(\mathrm{t}, J=9.7 \mathrm{~Hz}, 1 \mathrm{H})$ and $(\mathrm{m}, 1 \mathrm{H}), \Delta v=259.7 \mathrm{~Hz}$; 2. 82-2.66 (unresolved AB part of $\mathrm{ABX}$ system, m, 2H). ${ }^{13} \mathrm{C} \mathrm{NMR}\left(\mathrm{CD}_{3} \mathrm{OD}, 75 \mathrm{MHz}\right), \delta(\mathrm{ppm}): 158.0,156.3,134.2,130.3$, 128.7, 127.8, 127.2, 126.0, 115.1, 53.9, 50.9, 47.9, 38.9. HRMS $\left(\mathrm{ESI}^{+}\right): \mathrm{m} / \mathrm{z}=282.15985$ $[\mathrm{M}, \mathrm{H}]^{+}$found; $\mathrm{C}_{17} \mathrm{H}_{20} \mathrm{~N}_{3} \mathrm{O}$ calculated $\mathrm{m} / \mathrm{z}=282.16009[\mathrm{M}, \mathrm{H}]^{+}$. Mp: ${ }^{\circ} \mathrm{C} . \alpha_{\mathrm{D}}\left(20^{\circ} \mathrm{C}, \mathrm{CH}_{3} \mathrm{OH}\right)=$ $-0.014^{\circ}(0.500 \mathrm{mg} / \mathrm{mL}) . \mathrm{IR}, v\left(\mathrm{~cm}^{-1}\right): 3064,1670(\mathrm{C}=\mathrm{N})$. HPLC: $\mathrm{C}_{4}$ column: $\mathrm{t}_{\mathrm{R}}=10.2 \mathrm{~min}$, purity $99 \% \mathrm{C}_{18}$ column: $\mathrm{t}_{\mathrm{R}}=15.8 \mathrm{~min}$, purity $>99 \%$.

4.4.13. (4S)-1-benzyl-4-[(4-methoxyphenyl)methyl]imidazolidin-2-imine hydrochloride (13). According to general method 2, 13 was obtained (chromatography, $\mathrm{CH}_{2} \mathrm{Cl}_{2} /$ methanol 90/10) a brown solid (14 mg, 67\%). ${ }^{1} \mathrm{H}$ NMR $\left(\mathrm{CD}_{3} \mathrm{OD}, 300 \mathrm{MHz}\right), \delta(\mathrm{ppm}): 7.39-7.31$ (m, 5H); 7.09 $(\mathrm{d}, J=8.6 \mathrm{~Hz}, 2 \mathrm{H}) ; 6.83(\mathrm{~d}, J=6.6 \mathrm{~Hz}, 2 \mathrm{H}) ; 4.45(\mathrm{AB}$ system, $2 \mathrm{H}, J=15.8 \mathrm{~Hz}, \Delta v=37.3$ $\mathrm{Hz}$ ); 4.26-4.19 (unresolved X part of ABX system, m, 1H); 3.79 (s, 3H); 3.61 [AB part of ABX system (ft, $J=9.7 \mathrm{~Hz}, 1 \mathrm{H})$ and $(\mathrm{m}, 1 \mathrm{H}), \Delta v=90 \mathrm{~Hz}$ )]; 2.80 (unresolved AB part of $\mathrm{ABX}$ system, m, 2H). ${ }^{13} \mathrm{C} \mathrm{NMR}\left(\mathrm{CD}_{3} \mathrm{OD}, 75 \mathrm{MHz}\right), \delta(\mathrm{ppm}): 158.9,157.9,134.2,130.2$, 128.7, 127.9, 127.4, 127.3, 113.8, 54.3, 53.9, 50.9, 48.4, 48.1, 47.9, 38.9. HRMS (ESI $\left.{ }^{+}\right): \mathrm{m} / \mathrm{z}$ $=296.17555[\mathrm{M}, \mathrm{H}]^{+}$found; $\mathrm{C}_{17} \mathrm{H}_{20} \mathrm{~N}_{3} \mathrm{O}$ calculated $\mathrm{m} / \mathrm{z}=296.17574[\mathrm{M}, \mathrm{H}]^{+} . \mathrm{Mp}:{ }^{\circ} \mathrm{C} . \alpha_{\mathrm{D}}$ 
$\left(20^{\circ} \mathrm{C}, \mathrm{CH}_{3} \mathrm{OH}\right)=-0.045^{\circ}(0.500 \mathrm{mg} / \mathrm{mL}) . \mathrm{IR}, v\left(\mathrm{~cm}^{-1}\right): 3064,1670(\mathrm{C}=\mathrm{N})$. HPLC: $\mathrm{C}_{4}$ column: $t_{R}=13.3$ min, purity $99 \% \mathrm{C}_{18}$ column: $\mathrm{t}_{\mathrm{R}}=8.0 \mathrm{~min}$, purity $>99 \%$.

\subsection{In vitro testing.}

4.5.1. Displacement binding assays. Competition binding curves of the $\mathrm{A}_{2 \mathrm{~A}}$ receptor antagonist $\left[{ }^{3} \mathrm{H}\right]-\mathrm{ZM} 24135$ by the designed $\mathrm{A}_{2} \mathrm{~A}$ antagonists described above, were performed as before ${ }^{56}$ in Human HEK293 $\mathrm{A}_{2 \mathrm{~A}} \mathrm{R}$ membranes (Perkin Elmer). $0.5 \mu \mathrm{L}$ of membranes (0.5U of $\left.\mathrm{A}_{2 \mathrm{~A}} \mathrm{R}\right)$ were incubated with $\left[{ }^{3} \mathrm{H}\right]-\mathrm{ZM} 24135(2 \mathrm{nM})$ and increasing concentrations of the designed $\mathrm{A}_{2 \mathrm{~A}} \mathrm{R}$ antagonists $(0$ to $600 \mathrm{nM}$ ) in a final volume of $300 \mu \mathrm{L}$ in the presence of $1 \mathrm{U} / \mathrm{mL}$ of adenosine deaminase (Roche). All samples were assayed in duplicate. Non-specific binding was determined for each assay in the presence of the antagonist ZM-24135 (8.3nM). Microplates were incubated for 1 hour at room temperature and the reaction was stopped by vacuum filtration with a Skatron semi-automatic cell harvester with chilled incubation solution (pH 7.4, Tris 50mM MgCl 10mM) to filtermats $1.5 \mu \mathrm{m}$ (Molecular Devices). $3 \mathrm{~mL}$ of scintillation cocktail (OptiPhase 'HiSafe' 2, PerkinHelmer) were added and radioactivity bound to the filters was determined after 12 hours with an efficiency of 55-60\% for 2 minutes. Displacement reference curves were performed with ZM-24135 (0 to 6nM in 6\%, 40\% or $60 \%$ of DMSO) and CGS241680 (0 to $6 \mathrm{nM})$.

4.5.2. Cell culture and cytotoxicity assay. The human neuroblastoma cell line (SY5Y) was cultured in DMEM (Dulbecco's Modified Eagle Medium) (Gibco) supplemented with $2 \mathrm{mM}$ L-glutamine, $100 \mu \mathrm{g} / \mathrm{ml}$ streptomycin, $100 \mathrm{IU} / \mathrm{mL}$ penicillin, $1 \mathrm{mM}$ non-essential amino acids and $10 \%(\mathrm{v} / \mathrm{v})$ heat-inactivated foetal bovine serum (Sigma Aldrich), and grown at $37^{\circ} \mathrm{C}$ in a humidified incubator with $5 \% \mathrm{CO}_{2}$.

Cells were seeded at 2,000 cells per well onto 96-well plates in DMEM medium. Cells were starved for 24 hours to obtain synchronous cultures, and were then incubated in culture medium that contained various concentrations of test compounds, each dissolved in less than $0.1 \%$ DMSO. After 72 hours of incubation, cell growth was estimated by the colorimetric MTT (thiazolyl blue tetrazolium bromide) assay.

\section{Acknowledgments}

We express our thanks to Mariam Lamarti, Phillip James Brennan and Alice Cao for their contribution in organic synthesis and Amélie Barczyk for some in vitro cytotoxicity experiments. The $300 \mathrm{MHz}$ NMR facilities were funded by the Région Nord-Pas de Calais 
(France), the Ministère de la Jeunesse, de l'Education Nationale et de la Recherche (MJENR) and the Fonds Européens de Développement Régional (FEDER).

This work was supported by Lille 2 University, ANR « Adoratau », PRES Univ Lille Nord de France. Valeria Moas Heloire is the recipient of a fellowship from Lille 2 University.

\section{References and notes}

1. Welsch, M. E.; Snyder, S. A.; Stockwell, B. R. Curr. Opin. Chem. Biol. 2010, 14, 347.

2. In Scaffold Hopping inMedicinal Chemistry; Brown, N., Ed.; Wiley-VCH Verlag GmbH \& Co: 2014, p 1.

3. Evans, B. E.; Rittle, K. E.; Bock, M. G.; DiPardo, R. M.; Freidinger, R. M.; Whitter, W. L.; Lundell, G. F.; Veber, D. F.; Anderson, P. S.; L., C. R. S.; Lotti, V. J.; Cerino, D. J.; Kling, P. J.; Kunkel, K. A.; Springer, J. P.; Hirshfield, J. J. Med. Chem. 1988, 31, 2235.

4. Oxombre, B.; Lee-Chang, C.; Duhamel, A.; Toussaint, M.; Giroux, M.; Donnier-Marechal, M.; Carato, P.; Lefranc, D.; Zephir, H.; Prin, L.; Melnyk, P.; Vermersch, P. Br. J. Pharmacol. 2015, 172, 1769.

5. Venna, V. R.; Deplancke, D.; Melnyk, P.; Bordet, R. Fundam. Clin. Pharmacol. 2008, 22, 1.

6. Charton, J.; Cazenave Gassiot, A.; Girault-Mizzi, S.; Debreu-Fontaine, M. A.; Melnyk, P.; Sergheraert, C. Bioorg. Med. Chem. Lett. 2005, 15, 4833.

7. Toussaint, M.; Mousset, D.; Foulon, C.; Jacquemard, U.; Vaccher, C.; Melnyk, P. Eur. J. Med. Chem. 2010, 45, 256.

8. Toussaint, M.; Delair, B.; Foulon, C.; Lempereur, N.; Vaccher, C.; Maurice, T.; Melnyk, P. Eur. Neuropsychopharmacol. 2009, 19, 504.

9. Cazenave Gassiot, A.; Charton, J.; Girault-Mizzi, S.; Gilleron, P.; Debreu-Fontaine, M. A.; Sergheraert, C.; Melnyk, P. Bioorg. Med. Chem. Lett. 2005, 15, 4828.

10. Ma, Y.; De, S.; Chen, C. Tetrahedron 2015, 71, 1145.

11. Berlinck, R. G.; Trindade-Silva, A. E.; Santos, M. F. Nat. Prod. Rep. 2012, 29, 1382.

12. Berlinck, R. G.; Burtoloso, A. C.; Trindade-Silva, A. E.; Romminger, S.; Morais, R. P.; Bandeira, K.; Mizuno, C. M. Nat. Prod. Rep. 2010, 27, 1871.

13. Berlinck, R. G.; Burtoloso, A. C.; Kossuga, M. H. Nat. Prod. Rep. 2008, 25, 919.

14. Verbeken, M.; Wynendaele, E.; Mauchauffee, E.; Bracke, N.; Stalmans, S.; Bojnik, E.;

Benyhe, S.; Peremans, K.; Polis, I.; Burvenich, C.; Gjedde, A.; Hernandez, J. F.; De Spiegeleer, B. Peptides 2015, 63C, 10.

15. Anzini, M.; Chelini, A.; Mancini, A.; Cappelli, A.; Frosini, M.; Ricci, L.; Valoti, M.; Magistretti, J.; Castelli, L.; Giordani, A.; Makovec, F.; Vomero, S. J. Med. Chem. 2010, 53, 734.

16. de Lera Ruiz, M.; Lim, Y. H.; Zheng, J. J. Med. Chem. 2014, 57, 3623.

17. Rebola, N.; Rodrigues, R. J.; Lopes, L. V.; Richardson, P. J.; Oliveira, C. R.; Cunha, R. A. Neuroscience 2005, 133, 79.

18. Blum, D.; Hourez, R.; Galas, M. C.; Popoli, P.; Schiffmann, S. N. Lancet Neurol. 2003, 2, 366.

19. Chen, J. F.; Sonsalla, P. K.; Pedata, F.; Melani, A.; Domenici, M. R.; Popoli, P.; Geiger, J.; Lopes, L. V.; de Mendonca, A. Prog. Neurobiol. 2007, 83, 310.

20. Milne, G. R.; Palmer, T. M. TheScientificWorldJournal 2011, 11, 320.

21. Fredholm, B. B.; Chern, Y.; Franco, R.; Sitkovsky, M. V. Prog. Neurobiol. 2007, 83, 263. 
22. Popoli, P.; Blum, D.; Martire, A.; Ledent, C.; Ceruti, S.; Abbracchio, M. P. Prog Neurobiol 2007, 81, 331.

23. Matos, M.; Augusto, E.; Santos-Rodrigues, A. D.; Schwarzschild, M. A.; Chen, J. F.; Cunha, R. A.; Agostinho, P. Glia 2012, 60, 702.

24. Ribeiro, J. A.; Sebastiao, A. M. Acta Physiol. 2010, 199, 161.

25. Orr, A. G.; Orr, A. L.; Li, X. J.; Gross, R. E.; Traynelis, S. F. Nat. Neurosci. 2009, 12, 872 .

26. Gomes, C. V.; Kaster, M. P.; Tome, A. R.; Agostinho, P. M.; Cunha, R. A. Biochim. Biophys. Acta 2011, 1808, 1380.

27. Popoli, P.; Blum, D.; Domenici, M. R.; Burnouf, S.; Chern, Y. Curr. Pharm. Des. 2008, 14,1500 .

28. Preti, D.; Baraldi, P. G.; Moorman, A. R.; Borea, P. A.; Varani, K. Med. Res. Rev. 2015, 0,1 .

29. Jaakola, V. P.; Griffith, M. T.; Hanson, M. A.; Cherezov, V.; Chien, E. Y.; Lane, J. R.; Ijzerman, A. P.; Stevens, R. C. Science 2008, 322, 1211.

30. Katritch, V.; Jaakola, V. P.; Lane, J. R.; Lin, J.; Ijzerman, A. P.; Yeager, M.; Kufareva, I.; Stevens, R. C.; Abagyan, R. J. Med. Chem. 2010, 53, 1799.

31. Charton, J.; Gassiot, A. C.; Melnyk, P.; Girault-Mizzi, S.; Sergheraert, C. Tetrahedron Lett. 2004, 45, 7081.

32. Ishikawa, T. Chem. Pharm. Bull. 2010, 58, 1555.

33. Katritzky, A. R.; Rogovoy, B. V. Arkivoc 2005, iv, 49.

34. Suhs, T.; Konig, B. Mini-Rev. Org. Chem. 2006, 4, 315.

35. Cabordery, A.-C.; Toussaint, M.; Azaroual, N.; Bonte, J.-P.; Melnyk, P.; Vaccher, C.; Foulon, C. Tetrahedron: Asymmetry 2011, 22, 125.

36. Ma, D.; Cheng, K. Tetrahedron: Asymmetry 1999, 10, 713.

37. Lovick, H. M.; Michael, F. E. Tetrahedron Lett. 2009, 50, 1016.

38. Han, X.; Michne, J. A.; Pin, S. S.; Burris, K. D.; Balanda, L. A.; Fung, L. K.; Fiedler, T.; Browman, K. E.; Taber, M. T.; Zhang, J.; Dubowchik, G. M. Bioorg. Med. Chem. Lett. 2005, 15,3870 .

39. Li, Y.; Liang, J.; Siu, T.; Hu, E.; Rossi, M. A.; Barnett, S. F.; Defeo-Jones, D.; Jones, R. E.; Robinson, R. G.; Leander, K.; Huber, H. E.; Mittal, S.; Cosford, N.; Prasit, P. Bioorg. Med. Chem. Lett. 2009, 19, 834.

40. Latli, B.; D'Amour, K.; Casida, E. J. Med. Chem. 1999, 42, 2227.

41. Ma, Z.; Day, C. S.; Bierbach, U. J. Org. Chem. 2007, 72, 5387.

42. Wu, Y. Q.; Hamilton, S. K.; Wilkinson, D. E.; Hamilton, G. S. J. Org. Chem. 2002, 67, 7553.

43. Kubota, H.; Nakamura, Y.; Higashijima, T.; Yamamoto, Y.; Oka, K.; Igarashi, S. 2005; Vol. WO2005095395 (A2).

44. Ho, J. Z.; Braun, M. P.; Subramanian, R.; Gao, Y. D.; Dean, D. C.; Melillo, D. G. Helv. Chim. Acta 2004, 87, 674.

45. Hutchinson, J. H.; Halczenko, W.; Brashear, K. M.; Breslin, M. J.; Coleman, P. J.; Duong, L. T.; Fernandez-Metzler, C.; Gentile, M. A.; Fisher, J. E.; Hartman, G. D.; Huff, J. R.; Kimmel, D. B.; Leu, C. T.; Meissner, R. S.; Merkle, K.; Nagy, R.; Pennypacker, B.; Perkins, J. J.; Prueksaritanont, T.; Rodan, G.; Varga, S. L.; Wesolowski, G. A.; Zartman, A. E.; Rodan, S. B.; Duggan, M. E. J. Med. Chem. 2003, 46, 4790.

46. Ryckebusch, A.; Deprez-Poulain, R.; Maes, L.; Debreu-Fontaine, M. A.; Mouray, E.; Grellier, P.; Sergheraert, C. J. Med. Chem. 2003, 46, 542.

47. Dolomanov, O. V.; Bourhis, L. J.; Gildea, R. J.; Howard, J. A. K.; Puschmann, H. J. Appl. Crystallogr. 2009, 42, 339.

48. Malkov, A. V.; Vrankova, K.; Cerny, M.; Kocovsky, P. J. Org. Chem. 2009, 74, 8425. 
49. Xu, Z.; Cheng, F.; Da, C.; Liu, G.; Tang, Y. J Mol Model 2010, 16, 1867.

50. McHardy, T.; Caldwell, J. J.; Cheung, K. M.; Hunter, L. J.; Taylor, K.; Rowlands, M.; Ruddle, R.; Henley, A.; de Haven Brandon, A.; Valenti, M.; Davies, T. G.; Fazal, L.; Seavers, L.; Raynaud, F. I.; Eccles, S. A.; Aherne, G. W.; Garrett, M. D.; Collins, I. J. Med. Chem. 2010, 53, 2239.

51. Cheung, M.; Kuntz, K. W.; Pobanz, M.; Salovich, J. M.; Wilson, B. J.; Andrews, C. W., 3rd; Shewchuk, L. M.; Epperly, A. H.; Hassler, D. F.; Leesnitzer, M. A.; Smith, J. L.; Smith, G. K.; Lansing, T. J.; Mook, R. A., Jr. Bioorg. Med. Chem. Lett. 2008, 18, 6214.

52. Arnaud, O.; Koubeissi, A.; Ettouati, L.; Terreux, R.; Alame, G.; Grenot, C.; Dumontet, C.; Di Pietro, A.; Paris, J.; Falson, P. J. Med. Chem. 2010, 53, 6720.

53. Velmourougane, G.; Harbut, M. B.; Dalal, S.; McGowan, S.; Oellig, C. A.; Meinhardt, N.; Whisstock, J. C.; Klemba, M.; Greenbaum, D. C. J. Med. Chem. 2011, 54, 1655.

54. Sorto, N. A.; Painter, P. P.; Fettinger, J. C.; Tantillo, D. J.; Shaw, J. T. Org. Lett. 2013, 15, 2700.

55. Reginato, G.; Di Credico, B.; Andreotti, D.; Mingardi, A.; Paio, A.; Donati, D. Tetrahedron: Asymmetry 2007, 18, 2680.

56. Lopes, L. V.; Cunha, R. A.; Ribeiro, J. A. J. Neurophysiol. 1999, 82, 3196. 
List of captions

Table 1. ${ }^{a}$ Yield of the cyclization step. ${ }^{\mathrm{b}} \mathrm{A}_{2 \mathrm{a}} \mathrm{R}$ 's agonist CGS-21680 used as a reference $(\mathrm{Ki}=$ $0.503 \mu \mathrm{M})$. Displacement of specific $\left[{ }^{3} \mathrm{H}\right]-\mathrm{ZM} 241385$ binding in membranes obtained from $\mathrm{hA}_{2 \mathrm{a}}$ receptor stably expressed in HEK293 cells. ${ }^{\mathrm{c} C y t o t o x i c i t y ~ a s s a y s ~ o n ~ S Y 5 Y ~ c e l l s . ~}{ }^{\mathrm{c}} \mathrm{Ki}>$ $450 \mu \mathrm{M}$.

\section{Figure 1.}

Figure 2. $A_{2 A}$ R's crystal structure with (i) high-affinity antagonist ZM241385, (ii) Tic-H 1 and (iii) Tic-guanidine 2. Hydrogen bonds with Glu ${ }^{169}$ and $\mathrm{Asn}^{253}$ missing with Tic-H (ii) are being restored with the guanidine function (iii).

Figure 3. Pharmacomodulations of compounds 2-6 of the Tic-guanidine core using various amines in the reductive amination step.

Figure 4. Opening of the central Tic-guanidine core.

Figure 5. Thermal ellipsoid drawing ${ }^{47}$ (30\% probability) of the asymmetric unit of compound $\mathbf{2}$ (left) and $\mathbf{3}$ (right) showing the molecular structure and the labeling scheme.

Figure 6. Thermal ellipsoid drawing ${ }^{47}$ (30\% probability) of the asymmetric unit of compound 7-9 and 11 showing the molecular structure and the labeling scheme.

Scheme 1. i) $\mathrm{HNMe}(\mathrm{OMe}) . \mathrm{HCl}$, EDC, $\mathrm{HOBt}, \mathrm{NMM}, \mathrm{CH}_{3} \mathrm{CN}, \mathrm{CH}_{2} \mathrm{Cl}_{2}, 61 \%$; ii) $\mathrm{LiAlH}_{4}, \mathrm{THF}$ $0^{\circ} \mathrm{C}$ then aq. $\mathrm{KHSO}_{4}, 66 \%$; iii) $\mathrm{R}-\mathrm{NH}_{2}, \mathrm{NaHB}(\mathrm{OAc})_{3}, \mathrm{CH}_{2} \mathrm{Cl}_{2}$ then aq. $\mathrm{NaHCO}_{3}, 92 \%$-quant; iv) $\mathrm{BrCN}, \mathrm{NaHCO}_{3}, \mathrm{EtOH}, 54-97 \%$; v) $\mathrm{HCl}$, dioxane, 46-88\%.

Scheme 2. i) $\mathrm{HNMe}(\mathrm{OMe}) \cdot \mathrm{HCl}, \mathrm{EDC}, \mathrm{HOBt}, \mathrm{NMM}, \mathrm{CH}_{3} \mathrm{CN}, \mathrm{CH}_{2} \mathrm{Cl}_{2}, 36-86 \%$; ii) $\mathrm{LiAlH}_{4}$, THF $0^{\circ} \mathrm{C}$ then aq. $\mathrm{KHSO}_{4}, 20-97 \%$; iii) $\mathrm{Bn}-\mathrm{NH}_{2}, \mathrm{NaHB}(\mathrm{OAc})_{3}, \mathrm{CH}_{2} \mathrm{Cl}_{2}$ then aq. $\mathrm{NaHCO}_{3}$, $19-99 \%$; iv) $\mathrm{BrCN}, \mathrm{NaHCO}_{3}, \mathrm{EtOH}, 44-94 \%$; v) $\mathrm{HCl}$, dioxane, 23-90\%. 


\begin{tabular}{ccccc}
\hline Entry & Cpd & Yield $^{\mathbf{a}}$ & $\begin{array}{c}\text { Ki } \\
(\boldsymbol{\mu M})^{\mathbf{b}}\end{array}$ & $\begin{array}{c}\mathbf{C C}_{\mathbf{5 0}} \\
(\boldsymbol{\mu} \mathbf{M})^{\mathbf{c}}\end{array}$ \\
\hline $\mathbf{1}$ & $\mathbf{1}$ & $/$ & 44 & $>100$ \\
$\mathbf{2}$ & $\mathbf{2}$ & $46 \%$ & 64 & $>100$ \\
$\mathbf{3}$ & $\mathbf{3}$ & $67 \%$ & $>200$ & $>100$ \\
$\mathbf{4}$ & $\mathbf{4}$ & $69 \%$ & $>200$ & $>100$ \\
$\mathbf{5}$ & $\mathbf{5}$ & $82 \%$ & 35 & $>100$ \\
$\mathbf{6}$ & $\mathbf{6}$ & $88 \%$ & $>200$ & $>100$ \\
$\mathbf{7}$ & $\mathbf{7}$ & $27 \%$ & $>200$ & $>100$ \\
$\mathbf{8}$ & $\mathbf{8}$ & $67 \%$ & $>200$ & $>100$ \\
$\mathbf{9}$ & $\mathbf{9}$ & $90 \%$ & $>200$ & $>100$ \\
$\mathbf{1 0}$ & $\mathbf{1 0}$ & $29 \%$ & $>200$ & $>100$ \\
$\mathbf{1 1}$ & $\mathbf{1 1}$ & $53 \%$ & $>200$ & $>100$ \\
$\mathbf{1 2}$ & $\mathbf{1 2}$ & $73 \%$ & $>200$ & $>100$ \\
$\mathbf{1 3}$ & $\mathbf{1 3}$ & $67 \%$ & $>200$ & $>100$ \\
\hline & & & &
\end{tabular}

Table 1.

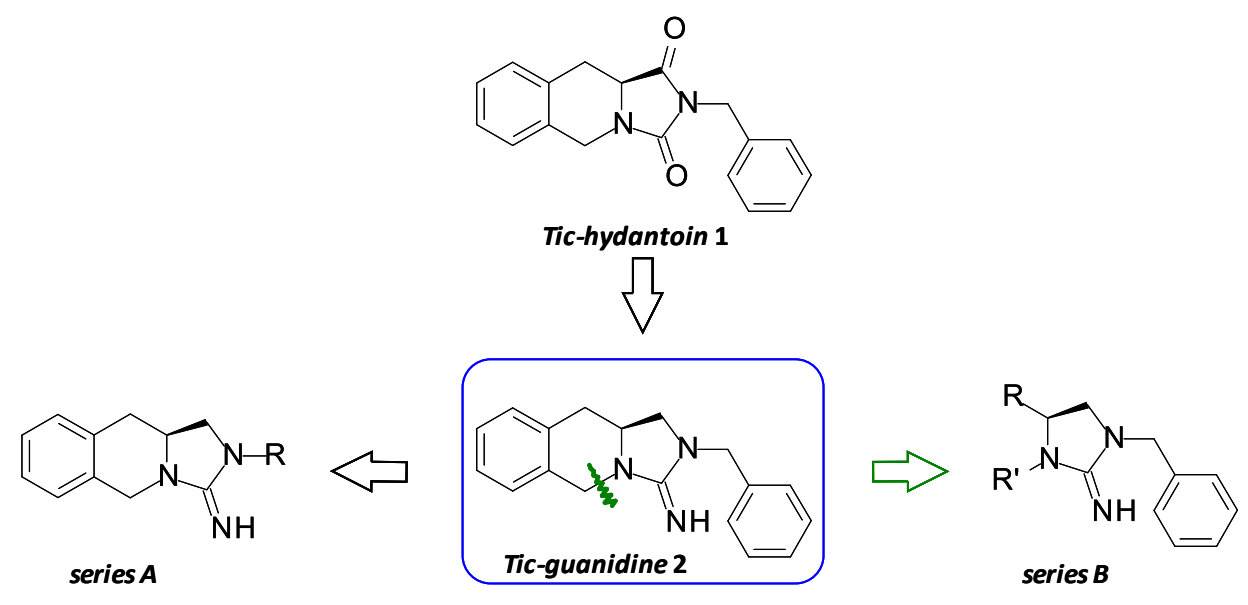

Figure 1. 


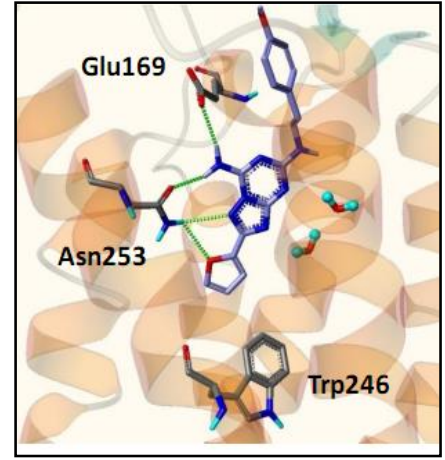

(i) ZM241385

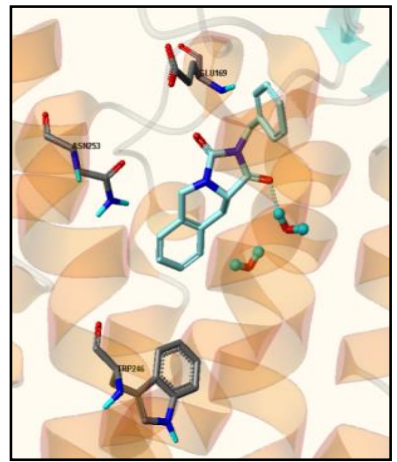

(ii) Tic-H 1

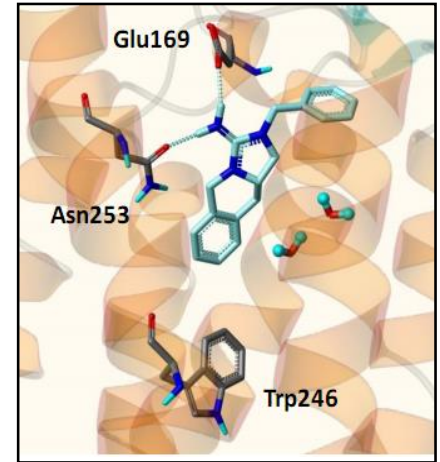

(iii) Tic-guanidine 2

Figure 2.

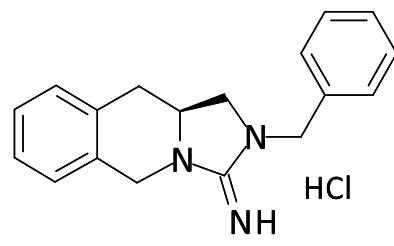

2

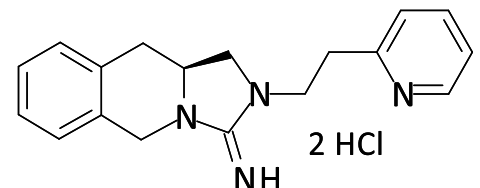

3<smiles>N=C1N(CCN2CCOCC2)CC2Cc3ccccc3CN12</smiles>

4

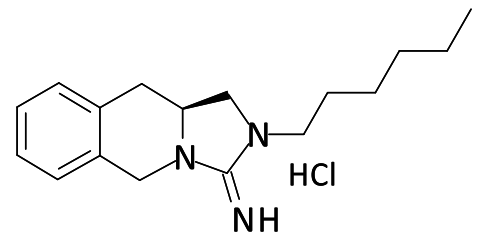

6

Figure 3.

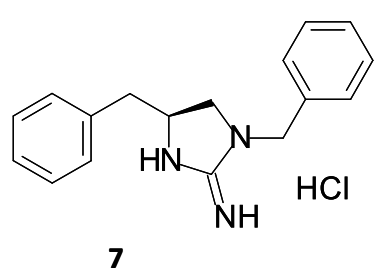<smiles>N=C1N(Cc2ccccc2)CC2CCCCN12</smiles>

10<smiles>CN1C(=N)N(Cc2ccccc2)CC1Cc1ccccc1</smiles><smiles>CC1CN(Cc2ccccc2)C(=N)N1</smiles>

11<smiles>N=C1NC(Cc2ccc(F)cc2)CN1Cc1ccccc1</smiles>

9<smiles>[R20]c1ccc(CC2CN(Cc3ccccc3)C(=N)N2)cc1</smiles>

$12 \mathrm{R}=\mathrm{H}$
$13 \mathrm{R}=\mathrm{M}$ 
Figure 4.
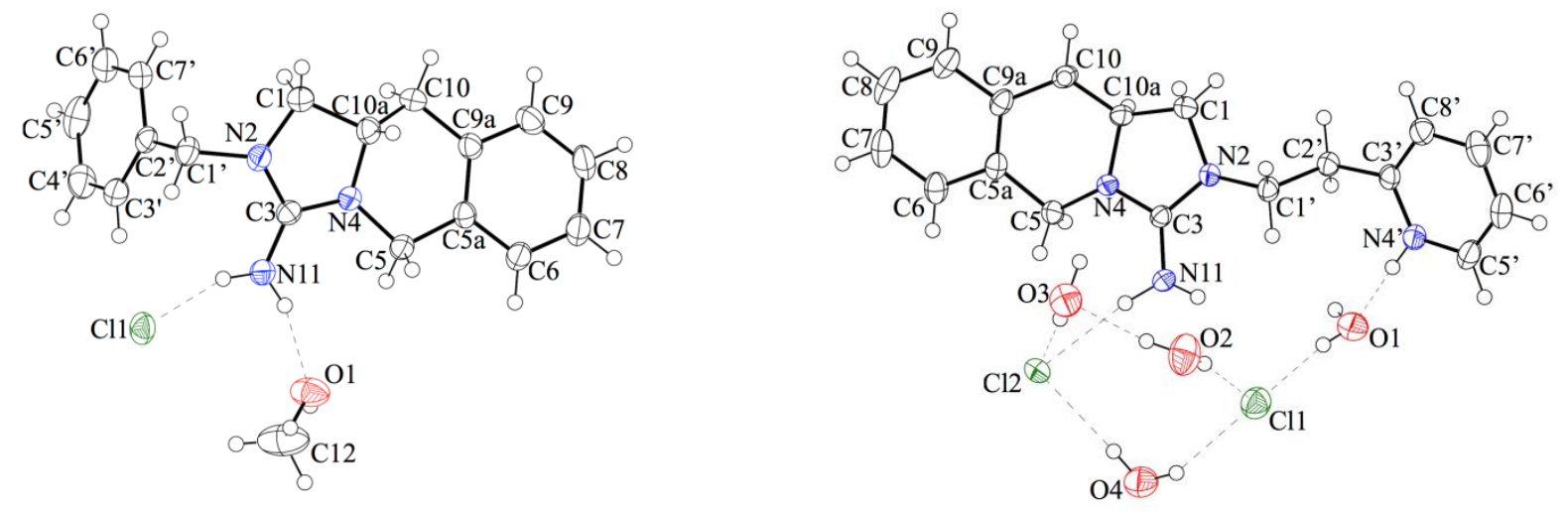

Figure 5.

(A)

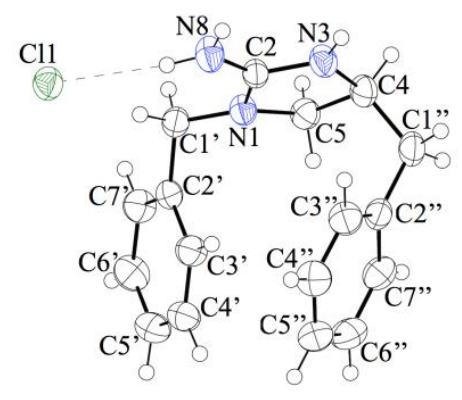

(1) $\mathrm{Cl1}$

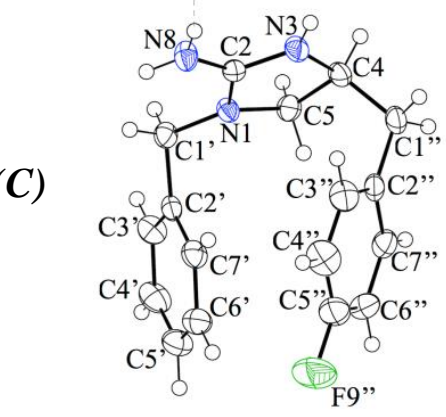

(B)

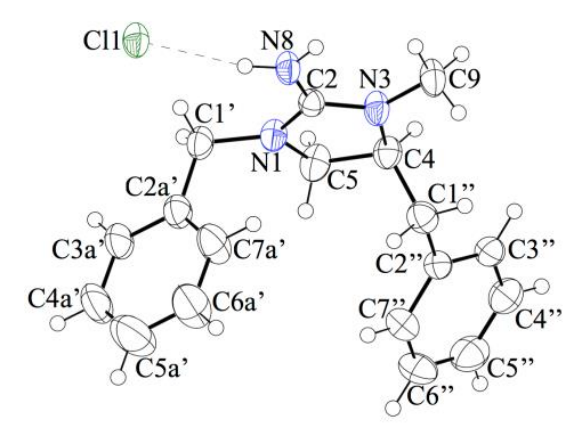

(D)

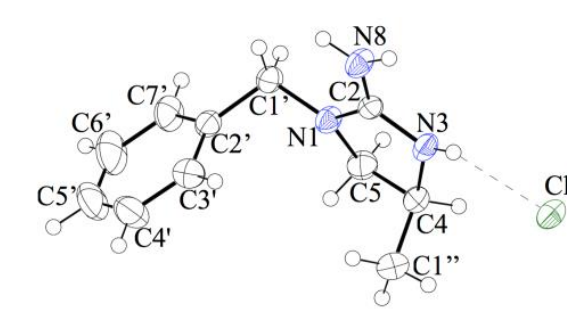

Figure 6. 


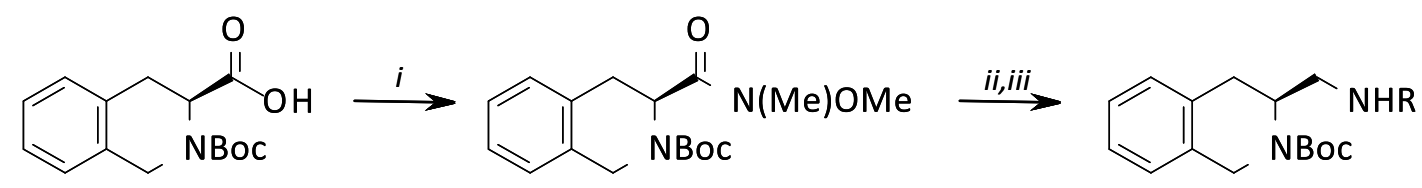

I

II

2b-6b

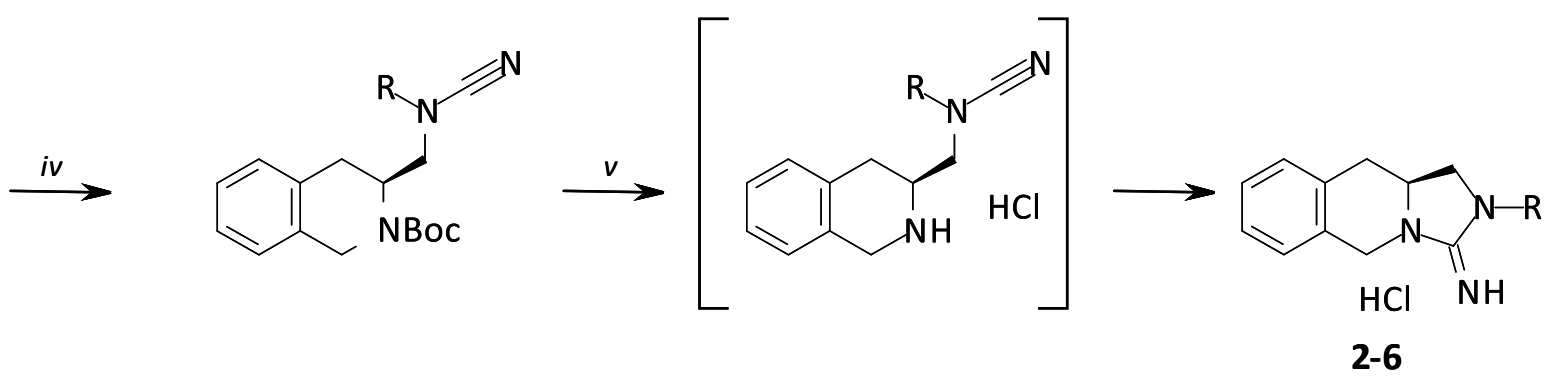

Scheme 1.

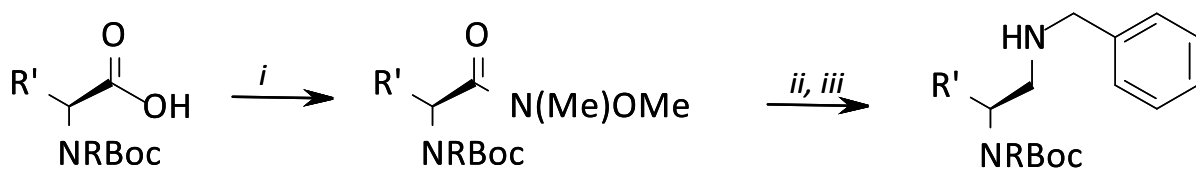

7a-13a

$7 b-13 b$

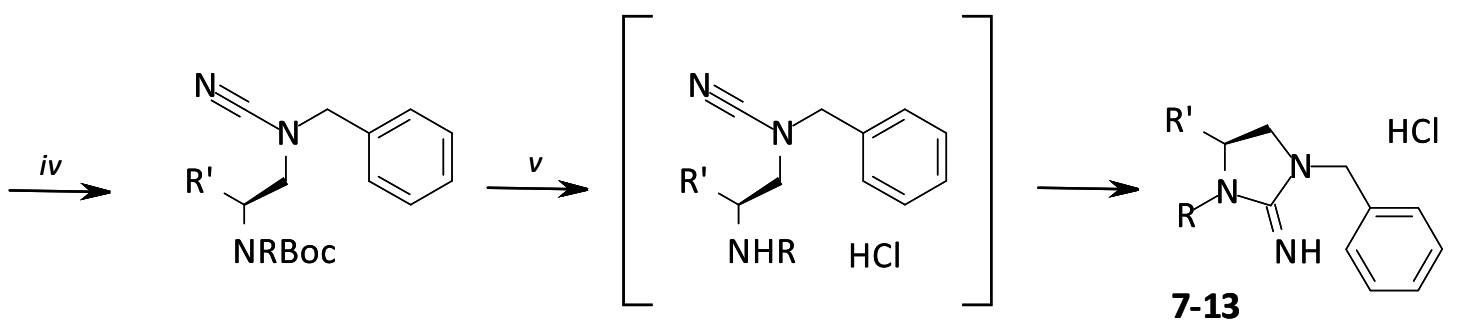

Scheme 2. 